Research article

Open Access

\title{
Tamoxifen induces pleiotrophic changes in mammary stroma resulting in extracellular matrix that suppresses transformed phenotypes
}

\author{
Rhonda Hattar ${ }^{1,2}$, Ori Maller1,3, Shauntae McDaniel' ${ }^{1}$, Kirk C Hansen ${ }^{4,5}$, Karla J Hedman 1 , \\ Traci R Lyons ${ }^{1}$, Scott Lucia 5,6 , R Storey Wilson Jr6 and Pepper Schedin ${ }^{1,2,3,4,7}$
}

\begin{abstract}
1Department of Medicine, Division of Medical Oncology, University of Colorado Denver, 12801 East 17th Avenue, Aurora, CO 80045, USA ${ }^{2}$ Program in Cell Biology, Stem Cells and Development, University of Colorado Denver, 12801 East 17th Avenue, Aurora, CO 80045, USA 3Program in Cancer Biology, University of Colorado Denver, 12801 East 17th Avenue, Aurora, CO 80045, USA ${ }^{4}$ Department of Pediatrics, University of Colorado Denver, 12801 East 17th Avenue, Aurora, CO 80045, USA 5 University of Colorado Comprehensive Cancer Center, University of Colorado Denver, 12801 East 17th Avenue, Aurora, CO 80045, USA ${ }^{6}$ Department of Pathology, University of Colorado Denver, 12801 East 17th Avenue, Aurora, CO 80045, USA

${ }^{7}$ AMC Cancer Research Center, University of Colorado Denver, 12801 East 17th Avenue, Aurora, CO 80045, USA
\end{abstract}

Corresponding author: Pepper Schedin, pepper.schedin@uchsc.edu

Received: 18 Jun 2008 Revisions requested: 8 Jul 2008 Revisions received: 16 Dec 2008 Accepted: 27 Jan 2009 Published: 27 Jan 2009

Breast Cancer Research 2009, 11:R5 (doi:10.1186/bcr2220)

This article is online at: http://breast-cancer-research.com/content/11/1/R5

(c) 2009 Hattar et al.; licensee BioMed Central Ltd.

This is an open access article distributed under the terms of the Creative Commons Attribution License (http://creativecommons.org/licenses/by/2.0), which permits unrestricted use, distribution, and reproduction in any medium, provided the original work is properly cited.

\begin{abstract}
Introduction The functional unit of the mammary gland has been defined as the epithelial cell plus its microenvironment, a hypothesis that predicts changes in epithelial cell function will be accompanied by concurrent changes in mammary stroma. To test this hypothesis, the question was addressed of whether mammary stroma is functionally altered by the anti-oestrogen drug tamoxifen.

Methods Forty female rats at 70 days of age were randomised to two groups of 20 and treated with $1.0 \mathrm{mg} / \mathrm{kg}$ tamoxifen or vehicle subcutaneously daily for 30 days, followed by a threeday wash out period. Mammary tissue was harvested and effects of tamoxifen on mammary epithelium and stroma determined.

Results As expected, tamoxifen suppressed mammary alveolar development and mammary epithelial cell proliferation. Primary mammary fibroblasts isolated from tamoxifen-treated rats displayed a three-fold decrease in motility and incorporated less fibronectin in their substratum in comparison to control fibroblasts; attributes indicative of fibroblast quiescence. Immunohistochemistry analysis of CD68, a macrophage lysosomal marker, demonstrated a reduction in macrophage infiltration in mammary glands of tamoxifen-treated rats. Proteomic analyses by mass spectrometry identified several

extracellular matrix (ECM) proteins with expression levels with tamoxifen treatment that were validated by Western blot. Mammary tissue from tamoxifen-treated rats had decreased fibronectin and increased collagen 1 levels. Further, ECM proteolysis was reduced in tamoxifen-treated rats as detected by reductions in fibronectin, laminin 1, laminin 5 and collagen 1 cleavage fragments. Consistent with suppression in ECM proteolysis with tamoxifen treatment, matrix metalloproteinase-2 levels and activity were decreased. Biochemically extracted mammary ECM from tamoxifen-treated rats suppressed in vitro macrophage motility, which was rescued by the addition of proteolysed collagen or fibronectin. Mammary ECM from tamoxifen-treated rats also suppressed breast tumour cell motility, invasion and haptotaxis, reduced organoid size in 3dimensional culture and blocked tumour promotion in an orthotopic xenograft model; effects which could be partially reversed by the addition of exogenous fibronectin.

Conclusions These data support the hypothesis that mammary stroma responds to tamoxifen treatment in concert with the epithelium and remodels to a microenvironment inhibitory to tumour cell progression. Reduced fibronectin levels and reduced ECM turnover appear to be hallmarks of the quiescent mammary microenvironment. These data may provide insight into attributes of a mammary microenvironment that facilitate tumour dormancy.
\end{abstract}

3D: three-dimensional; BrdU: bromodeoxyuridine; DMEM: Dulbecco's modified eagle medium; ECM: extracellular matrix; EDTA: ethylenediaminetetraacetic acid; EGF: epidermal growth factor; EGFR: epidermal growth factor receptor; ER: oestrogen receptor; FCS: fetal calf serum; GAPDH: glyceraldehyde 3-phosphate dehydrogenase; H\&E: haematoxylin and eosin; LN: laminin; MEC: mammary gland epithelial cells; MG: mammary gland; MMP: matrix metalloproteinase; MT1-MMP: membrane type 1 matrix metalloproteinase; MW: molecular weight; NBF: neutral buffered formalin; NIH: National Institutes of Health; PBS: phosphate buffered saline; PR: progesterone receptor; RCF: relative centrifugal force; SEM: standard error of the mean; TGF $\beta$ : tumour growth factor beta. 


\section{Introduction}

Once thought of as a passive support structure, the mammary microenvironment is composed of a complex mix of cellular, structural and soluble components capable of fundamentally altering mammary epithelial cell specificity and behaviour [1]. Consequently, the functional unit of the mammary gland is now recognised as the epithelial cell plus its extracellular matrix (ECM) and stromal and immune cells embedded therein [2]. Fibroblasts are primarily responsible for deposition of the stromal ECM. It is anticipated that for each organ fibroblasts deposit tissue-specific ECM [3]. The model of dynamic reciprocity postulates that the microenvironment, in particular the $E C M$, exerts an influence on gene expression in the mammary epithelial cell and, in turn, gene expression of the epithelial cell influences stromal cells and the composition of the ECM $[2,4]$. In support of this concept, our laboratory has shown that the composition of rat mammary ECM is dependent on reproductive state, demonstrating that the mammary microenvironment, as with the mammary epithelium, is under endocrine control [5]. Further, mammary ECM isolated from distinct hormonal states was found to facilitate epithelial cell proliferation, differentiation, death and glandular reorganisation in 3-dimensional (3D) cell culture, recapitulating events that occur in vivo with the pregnancy-involution cycle. Work by others has shown that the mammary ECM protein fibronectin and its specific integrin $\alpha 5 \beta 1$ are under hormonal control and in turn mediate hormone response in mammary epithelium, providing further support for the concept of Dynamic Reciprocity in the mammary gland $[6,7]$.

Given the dynamic and reciprocal relation between ECM and normal mammary epithelial cells, it is not surprising that the microenvironment also exerts a significant effect on tumour cell behaviour [8]. Early evidence for stromal impact on cancer progression was observed by histological analyses; as wound healing-associated modifications in stroma, termed desmoplasia, were shown to contribute to poor prognosis in many human cancers, including breast, colon and prostate [9-14]. More surprisingly, even physiological changes in the mammary microenvironment have been demonstrated to influence tumour cell progression [5,15-17]. For example, mammary ECM isolated from mammary glands undergoing weaninginduced involution promotes breast tumour cell motility and invasion in vitro and metastasis in a xenograft model of breast cancer, whereas ECM isolated from quiescent virgin mammary tissue did not support these tumour cell attributes $[15,17]$. Mammary involution ECM is characterised in part by partial proteolysis of fibronectin and laminin, high-fibrillar collagen content, and increased matrix metalloproteinase (MMP) activity; all of which have been implicated in tumour progression $[5,17,18]$. Thus, evidence suggests that both pathological - and physiological-induced changes in mammary stroma contribute to breast cancer progression.

Whether the microenvironment can actively inhibit tumour progression has not been well studied. It is known that tumour cells can arrive at secondary sites in high numbers but fail to expand [19] and that microtumours and solitary tumour cells can reside in a dormant state for decades [20-22]. These data suggest that the microenvironment can indeed exert a significant protective effect. Experimental proof of this principle lies in studies in which malignant cells undergo a phenotypic reversion to polarised epithelium when exposed to a tissue-normalising ECM milieu [23-25]. Further, morphologically normal epithelial tissue adjacent to breast tumours can display loss of heterozygosity similar to that of the tumour, but without manifesting tumour cell characteristics [26]. One explanation is that malignant progression of these mutant, but morphologically normal, cells is inhibited by the local tissue microenvironment. Cumulatively, these data strongly suggest that the microenvironment can impart a dormant suppressive phenotype on malignant cells.

In this study, we tested the hypothesis that the stromal compartment responds with the epithelium to interventions that reduce breast cancer risk. Specifically, we addressed whether tamoxifen treatment alters the composition and function of mammary ECM in a manner consistent with supporting tumour cell dormancy. Tamoxifen is the endocrine treatment of choice for pre-menopausal women with breast cancer and a proven chemopreventive agent in high-risk patients [27]. Its canonical mechanism is as an anti-proliferative agent in oestrogen receptor (ER) positive mammary tumour cells [28]. Our data support the hypothesis that mammary stroma responds to tamoxifen treatment and remodels to an environment that would be inhibitory to breast cancer progression.

\section{Materials and methods}

\section{Tamoxifen study experimental design}

Forty female Sprague-Dawley rats, 73 days of age (HarlanTeklad, Indianapolis, IN, USA) were randomised by weight into two groups of 20. Rats in the tamoxifen group were injected subcutaneously daily with $1 \mathrm{mg} / \mathrm{kg}$ tamoxifen (Sigma, St. Louis, MO, USA) dissolved in ethanol and suspended in sesame oil. The vehicle control group was injected daily with an equal volume of ethanol/sesame oil solvent. After 30 days of treatment, lymph-node-free right inguinal mammary glands were harvested, snap frozen and stored at $-80^{\circ} \mathrm{C}$ for subsequent ECM isolation and biochemical analyses. To limit variations in ECM composition that may accompany oestrous cycling in the control group, phase of oestrous cycle was determined by daily cervical lavages and all control rats were sacrificed in the dioestrus 1 phase of the cycle, as previously 
described [29]. Cervical tissue was also collected for histological confirmation of oestrous cycle. The animal experiments were performed in duplicate. All animal procedures were performed in compliance with the AMC Cancer Research Institute and University of Colorado Denver Animal Care and Use Committees and National Institutes of Health (NIH) Policy on Humane Care and Use of Laboratory Animals.

\section{Primary fibroblast isolation}

Left inguinal mammary glands (lymph nodes removed) were processed for fibroblast isolation immediately after sacrifice using a protocol provided by Kornelia Polyak which has been previously reported [30]. Briefly, the tissue was minced and incubated in collagenase. After incubation, the tissue was processed through a series of centrifugations to separate fibroblasts. Isolated cells were confirmed to be fibroblast-like when they tested negative for pan-cadherin and pan-cytokeratin and positive for vimentin by Western blot analyses (data not shown), and are referred herein as fibroblasts; however, endothelial cell specific markers were not evaluated. Fibroblasts, used at passage three, were maintained in Dulbecco's modified eagle medium (DMEM)/F12 media (Hyclone, Logan, UT, USA) supplemented with $25 \mathrm{mM}$ Hepes (Sigma, St. Louis, MO, USA), 2 mM L-glutamine (Sigma, St. Louis, MO, USA), $50 \mu \mathrm{g} / \mathrm{mL}$ gentamicin (Sigma, St. Louis, MO, USA) and 20\% FCS (Sigma, St. Louis, MO, USA).

\section{Fibroblast motility assay}

Transwell $8 \mu \mathrm{m}$ pore filters in a 24-well plate format (Becton Dickinson, Franklin Lakes, NJ, USA) were overlaid with $50 \mu \mathrm{L}$ bovine gelatin, type B (Sigma, St Louis, MO, USA) at a concentration of $10 \mu \mathrm{g} / \mathrm{mL}$ and dried overnight. Five $\times 10^{4} \log$ phase primary fibroblasts at passage three were suspended in incomplete media and plated into the upper chamber. The lower chamber contained $1 \%$ fetal bovine serum as chemoattractant. The number of motile cells, evaluated four hours after plating, was quantified as previously described [15]. The assay was performed in quadruplicate and data are expressed as mean \pm standard error of the mean (SEM).

\section{Fibroblast-derived 3-dimensional matrices}

Primary mammary fibroblasts were pooled according to group, and $2 \times 10^{5}$ cells were plated into six-well plates pre-coated with $50 \mu \mathrm{l}$ of $2 \mu \mathrm{g} / \mathrm{ml}$ rat tail collagen (BD Biosciences, Bedford, MA, USA). Fibroblasts were cultured for 10 days in complete media, which was changed every two days. To isolate underlying ECM, fibroblasts were lysed in $20 \mathrm{mM}$ ammonium hydroxide and $0.5 \%$ Triton X-100 followed by several washes in PBS and water, according to the published protocol by Cukierman [31]. The cell-free underlying ECM was scraped from plates and stored at $-80^{\circ} \mathrm{C}$ for proteomic analysis.

\section{Histology}

Whole mount mammary glands were fixed in methacarn, processed in a series of ethanol and xylene (Fisher, Fair Lawn, New
Jersey, USA), stained with alum carmine (Fisher, Fair Lawn, New Jersey, USA), and bagged in methyl salicylate (Fisher, Fair Lawn, New Jersey, USA), as previously described [32]. Cervical tissue was also harvested, fixed in $10 \%$ neutral buffered formalin (NBF) for 18 hours, paraffin embedded, cut into $5 \mu \mathrm{m}$ sections and stained with H\&E. To control for morphological differences due to natural variation along the proximal/ distal mammary gland axis, mammary tissue associated with the dissected lymph regions of gland number 4 were fixed in $10 \%$ NBF for 18 hours and processed for H\&E staining as described above. The changes in mammary ductal and alveolar morphology in response to tamoxifen treatment were evaluated in these $5 \mu \mathrm{m} \mathrm{H \& E}$-stained sections as previously described [32].

For detection of fibrillar collagen, $5 \mu \mathrm{m}$ sections of mammary tissue were stained with sirius red F3B according to published methods [33] and counterstained with Weigert's iron haematoxylin. Mammary gland collagen staining was classified into three grades. Grade 1 glands had fat pads composed primarily (more than $50 \%$ ) of adipocytes and were free of dense interlobular collagen. Grade 2 glands had mixed fat pad morphology, with both adipocyte and fibrillar collagen-rich regions. Grade 3 glands had stroma dominated by fibrillar collagen. Collagen scoring was performed on coded slides by two independent investigators.

\section{Immunohistochemistry}

Samples of $4 \mu \mathrm{m}$ tissue were pretreated in $10 \mathrm{mM}$ sodium citrate at $90^{\circ} \mathrm{C}$ for 20 minutes. Bromodeoxyuridine (BrdU; BD Immunocytometry Systems, San Jose, CA, USA, for rat tissue; Dako, Santa Barbara, CA, USA, for mouse tissue) and the macrophage marker CD68 (Serotec, Oxford, UK) were detected with a standard avidin biotin complex-peroxidase method with 3,3'-diaminobenzidine as the chromagen.

\section{Mammary ECM isolation}

Mammary ECM isolation was performed based on a previously described protocol [5], using pooled inguinal mammary gland tissue from at least six rats per group. Briefly, frozen inguinal mammary glands, with lymph nodes removed, were pulverised, homogenised and extracted in a high salt/ $\mathrm{N}$-ethylmaleimide solution (3.4 M sodium chloride, $50 \mathrm{mM}$ Tris-hydrochloric acid $\mathrm{pH} 7.4,4 \mathrm{mM}$ ethylenediaminetetraacetic acid (EDTA), $2 \mathrm{mM}$ $\mathrm{N}$-ethylmaleimide) containing protease inhibitor cocktail (100 $\mu \mathrm{g} / \mathrm{ml}$ phenylmethylsulphonyl fluoride, $50 \mu \mathrm{g} / \mathrm{ml}$ each of aprotinin, leupeptin and pepstatin), at $4^{\circ} \mathrm{C}$ (chemicals purchased from Sigma, St Louis, MO, USA). Homogenates were enriched for ECM by two cycles of centrifugation (relative centrifugal force $(R C F)_{\max } 110,000 \times \mathrm{g}, 30$ minutes, $\left.4^{\circ} \mathrm{C}\right)$. The ECM-enriched pellets were resuspended in mid-salt/urea solution with proteinase inhibitor cocktail and extracted overnight at $4^{\circ} \mathrm{C}$. Samples were pelleted at $\mathrm{RCF}_{\max } 110,000 \times \mathrm{g}$, and the ECM-enriched supernatants extensively dialysed (MWCO 12-14,000 kDa, Spectrum) against low salt buffer 
followed by dialysis against sera-free media (DMEM/F12 media (Sigma, St Louis, MO, USA) supplemented with $1 \mu \mathrm{g} /$ $\mathrm{ml}$ gentamicin) at $4^{\circ} \mathrm{C}$. ECM were stored on ice at $4^{\circ} \mathrm{C}$ and used within two weeks of isolation. As reported previously, ECM protein integrity is stable under these storage conditions [5]. For the in vitro studies, all experiments were performed with two distinct batches of ECM in at least duplicate.

\section{ECM proteomics}

Aliquots of the mammary ECM isolates were subjected to insolution tryptic digestion for label-free mass spectrometrybased analysis. Each sample was reduced and alkylated with $5 \mathrm{mM}$ dithiothreitol and $20 \mathrm{mM}$ iodoacetamide after the addition of Rapigest (Waters Technologies, Millford, MA, USA) to $0.1 \%$. Trypsinisation was carried out overnight at $37^{\circ} \mathrm{C}$ and the reaction stopped by adding formic acid to a final concentration of $1 \%$. Centrifugation was used to remove the hydrolytic detergent and sample zip tipped (Millipore, Temecula, CA, USA) to remove salts.

For electrospray ionisation mass spectrometry, each of the samples $(2 \mu \mathrm{L})$ was injected onto a reverse-phase column using a chilled $\left(9^{\circ} \mathrm{C}\right)$ autosampler (Eksigent; Dublin, CA, USA) connected to a high-performance liquid chromatography system run at $0.12 \mu \mathrm{L} /$ minute before a passive split that resulted in about a $400 \mathrm{~nL} /$ minute post-split flow (Aligent; Santa Clara, CA, USA). A gradient of $12 \%$ to $30 \%$ acetonitrile (40 minutes) was applied over a two-hour run for peptide separation. The column effluent was coupled directly to a LTQ XL Linear Ion Trap mass spectrometer (Thermo/Finnigan; San Jose, CA, USA) with an in-house built nanospray ion source. Data acquisition was performed using the Xcalibur (version 2.0.6) software supplied with the instrument. The 60 minute liquid chromatography (LC) runs were monitored by sequentially recording the precursor scan (MS) followed by three collisioninduced dissociation acquisitions (MS/MS). Singly charged ions were excluded from collision induced disassociation (CID) selection. Normalised collision energies were employed using helium as the collision gas. An in-house script was used to create de-isotoped centroided peak lists from the raw spectra (mgf format). These peak lists were searched against the SwissProt (V51.6) database using an in-house developmental Protein Prospector LC Batch-Tag Web (Version 4.25.2, UCSF, San Francisco, CA, USA) and an in-house Mascot server (Version 2.2, Matrix Science, Boston, MA, USA). For searches mass tolerances were $\pm 0.6 \mathrm{Da}$ for MS peaks $(+1$ ${ }^{13} \mathrm{C}$ option), and $\pm 0.6 \mathrm{Da}$ for MS/MS fragment ions. Trypsin specificity was used allowing for one missed cleavage. The modifications of met oxidation, protein $\mathrm{N}$-terminal acetylation, peptide $\mathrm{N}$-terminal pyroglutamic acid formation were allowed for. Samples were searched against all rat and mouse entries in the protein database.

\section{Western blot analysis}

Tissues from mammary glands were analysed by Western Blot as previously described [5]. The following antibodies were used: polyclonal rabbit anti-rat fibronectin (1:250 Life Technologies, Gaithersburg, MD, USA), polyclonal rabbit anti-laminin (1:500 Novus Biologicals, Littleton, CO, USA), mouse antilaminin 5 ( $\gamma 2$ chain) monoclonal antibody $(1: 1000$, Chemicon International, Temecula, CA, USA), collagen 1 (1:1000, Abcam, Cambridge, MA, USA) and protein A secondary antibody (1:10,000 Amersham, Piscataway, NJ, USA). Monoclonal mouse anti-glyceraldehyde 3-phosphate dehydrogenase (GAPDH; 1:500 Amersham, Piscataway, NJ, USA) followed by an anti-mouse secondary (1:5,000 Santa Cruz Biotechnology, Santa Cruz, CA, USA) was used for protein loading controls. Signal was obtained using ECL western detection kit (Amersham, Piscataway, NJ, USA). For fibronectin and collagen 1 Westerns, $3.3 \mu \mathrm{g}$ of respective tissue samples were loaded per lane. For laminin (LN) westerns and zymogen assays, $9.5 \mu \mathrm{g}$ of respective tissue samples were loaded per lane.

\section{Zymogen assay}

Substrate gel analyses were performed as described [15]. Briefly, ECM samples loaded by equal protein were electrophoresed under non-reducing conditions on a $7.5 \%$ SDSPAGE containing $3 \mathrm{mg} / \mathrm{ml}$ porcine gelatin (Sigma, St. Louis, $\mathrm{MO}$, USA). Gels were incubated at $37^{\circ} \mathrm{C}$ for 72 hours in substrate buffer. Proteinase activity was visualised by Coomassie Blue 250 staining. Zymogen activity appears as a cleared band in a dark background. Semi-quantitative data was obtained by scanning densitometry of four independent lanes per condition with data analysed using BioRad Quantity One software (Bio-Rad, Hercules, CA, USA).

\section{Cell lines}

J774 murine macrophage cells, a generous gift from Dr Douglas Graham, were cultured in DMEM/high glucose medium (Hyclone Laboratories, Logan, Utah, USA) supplemented with $10 \%$ heat-inactivated FCS as previously described [34]. MCF-12A cells are a non-tumourigenic human immortalised mammary epithelial cell line [35]. V12 Ras-transformed MCF$12 \mathrm{~A}$ cells were previously described [36]. MCF-12A and MCF-12A-ras cells were grown in complete media consisting of Ham's F12/DMEM (Gibco, Carlsbad, CA, USA) containing $100 \mathrm{ng} / \mathrm{ml}$ cholera toxin (Gibco/BRL, Carlsbad, CA, USA), 0.5 $\mu \mathrm{g} / \mathrm{ml}$ hydrocortisone (Sigma, St. Louis, MO, USA), $10 \mu \mathrm{g} / \mathrm{ml}$ insulin (Sigma, St. Louis, MO, USA), $20 \mathrm{ng} / \mathrm{ml}$ epidermal growth factor (EGF) (Sigma, St. Louis, MO, USA) and 5\% horse serum (Gibco/BRL, Carlsbad, CA, USA). MDA-MB-231 cells (ATCC, Manassas, VA, USA), a human breast cancer cell line, were passaged into nude mice (mammary fat pad) and back out to plastic for at least four cycles as previously described [17]. The resulting variant cell line, which was enriched in the ability to grow in the fat pad was carried in MEM Alpha Media (Gibco, Carlsbad, CA, USA) completed 
with $2.2 \mathrm{~g} / \mathrm{L}$ of sodium bicarbonate, 1\% Hepes, 1\% Lglutamine, $10 \%$ heat inactivated FCS, $1 \mu \mathrm{g} / \mathrm{ml}$ of insulin, $1 \%$ sodium pyruvate and $1 \%$ non-essential amino acids.

\section{Transwell filter assays}

Motility assay

Log-phase murine macrophage $\mathrm{J} 774$ cells $\left(1 \times 10^{5}\right)$ were suspended in $200 \mu \mathrm{L}$ of DMEM/high-glucose medium (Hyclone Laboratories, Logan, Utah, USA) and plated on transwell $8 \mu \mathrm{m}$ pore filters in a 24-well plate format (Becton Dickinson, Franklin Lakes, NJ, USA). The lower chamber contained $800 \mu \mathrm{L}$ of $10 \mu \mathrm{g} / \mathrm{mL}$ control or tamoxifen mammary matrix with or without $10 \mu \mathrm{g} / \mathrm{mL}$ of rat tail collagen type 1 (BD Biosciences, Bedford, MA, USA), $10 \mu \mathrm{g} / \mathrm{mL}$ of bovine skin gelatin, type B (Sigma, St. Louis, MO, USA) or $10 \mu \mathrm{g} / \mathrm{mL}$ of human plasma fibronectin (Collaborative Biochemical, Bedford, MA, USA). Eight hours post-plating, cells were fixed with 10\% NBF, stained with $0.1 \%$ crystal violet and number of motile cells quantitated as previously described [15]. For tumour cell motility assays, log phase MDA-MB-231 cells $\left(5 \times 10^{4}\right.$ cells $)$ were suspended in $10 \mu \mathrm{g} / \mathrm{mL}$ control or tamoxifen mammary gland ECM, and overlaid onto transwell $8 \mu \mathrm{m}$ pore filters as described above. In the lower chamber, $1.0 \%$ horse serum was used as a chemoattractant and number of motile cells evaluated after 21 hours after plating. Motility assays were performed in quadruplicate and data are expressed as mean \pm SEM.

\section{Invasion assay}

Transwell $8 \mu \mathrm{m}$ pore filters in 24-well plate format (BD Biosciences, Bedford, MA, USA), were overlaid with $50 \mu \mathrm{L}$ control or tamoxifen mammary ECM at a concentration of $200 \mu \mathrm{g} /$ $\mathrm{mL}$ and dried overnight. Log-phase MCF12A-ras cells $(5 \times$ $10^{4}$ cells), were suspended in incomplete media and plated into the upper chamber. The lower chamber contained $0.5 \%$ horse serum as chemoattractant. The number of invasive cells, evaluated 24 hours post plating, was quantified as previously described [15]. The assay was performed in quadruplicate and data are expressed as mean \pm SEM.

Haptotaxis assay

Transwell $8 \mu \mathrm{m}$ pore filters were underlaid (coated on the bottom of the filter) with $50 \mu \mathrm{L}$ control or tamoxifen mammary ECM at a concentration of $75 \mu \mathrm{g} / \mathrm{mL}$ and dried overnight. Logphase MDA-MB-231 cells $\left(5 \times 10^{4}\right.$ cells) were suspended in incomplete media and plated into the upper chamber. The lower chamber contained incomplete media; the ECM on the filter served as chemoattractant. The number of invasive cells, evaluated four hours post plating, was quantified as described above. For all transwell filter assays, differences between control and experimental conditions were determined using the two-tailed t-test.

\section{3-dimensional culture model}

Ras-transformed MCF-12A and MDA-MB-231 cells were cultured in 3D culture as previously described [5]. Briefly, log- phase cells were harvested and overlaid onto $2 \mathrm{~mm}$ thick matrix pads at cell concentrations of $4.5 \times 10^{4}(\mathrm{MCF}-12 \mathrm{~A})$ or $1.5 \times 10^{4}$ (MDA-MB-231) or pre-coated with respective matrices with and without $20 \mu \mathrm{g} / \mathrm{mL}$ fibronectin (Collaborative Biochemical, Bedford, MA, USA) before overlaying onto the matrix pad, using a 96-well format (Sarstedt, Newton, NC, USA). The matrix substratum was composed of $50 \mu \mathrm{L}$ of nulliparous or tamoxifen-treated rat mammary gland ECM (normalised for total protein concentration) mixed 1:1 with Matrigel (BD Biosciences, San Jose, CA, USA) to facilitate polymerisation of endogenous mammary ECM. For control conditions, the pad was composed of Matrigel, without endogenous mammary ECM and controlled for total protein concentration. For MCF-12A cells, 5\% horse serum was added to the matrix pads. 3D culture assays were performed in triplicate and each experiment performed in duplicate with two different batches of endogenous mammary ECM.

\section{Image acquisition and quantitation}

Five micron sections of $3 \mathrm{D}$ organoids capturing top, middle and bottom representative areas of the matrix pad were $\mathrm{H} \& \mathrm{E}$ stained and imaged at $20 \times$ using an Aperio Scan Scope T3 System, (Vista, CA, USA) at a resolution of 1 pixel/0.5 $u$ and then down-sampled to a resolution of 1 pixel/2.4 $u$. Primary identification of cell clusters (organoids) was accomplished using NIH ImageJ (version 1.41o with Java 1.6.0_10.) that had been customised for colorimetric, size and circularity threshold gating steps using custom written plug-ins in the Java programming language. These image analysis algorithms were designed to identify and quantify immunohistochemical and morphological characteristics of $3 D$ organoids. Image preprocessing procedures were applied to identify and remove from subsequent analyses images with scanning and staining errors. Images that passed these filters were analysed using a series of algorithms. The primary image algorithms relied on identifying histochemical features through colorimetric thresholds. Secondary pass morphometric quantifications focused on area and circularity measurements for feature identification. This automated algorithmic-targeted image analysis was utilised to eliminate intra-observer and inter-observer variability and results in a repeatable mathematically quantifiable set of data. The number of organoids analysed was 1456 in the Matrigel group, 1516 in the control mammary ECM group and 709 in the tamoxifen mammary ECM group. Mean cell cluster sizes were compared across treatment groups. Given that the data were not normally distributed, significance was evaluated using the Kruskal-Wallis, non-parametric test. Alternatively, 308 tamoxifen organoids and 241 tamoxifen plus fibronectin organoid images were captured under light microscopy and $\mathrm{NIH}$ ImageJ (version 1.41o with Java 1.6.0_10.) utilised to determine the average area per organoid, and differences determined using the Mann-Whitney U Test. 


\section{Xenograft model}

Forty eight-week old female homozygous $\mathrm{Nu} / \mathrm{Nu}$ athymic nude mice ( $\mathrm{NCl}$, Frederick, MD, USA) were randomised by weight into two groups of 20. The animals were anaesthetised using isoflurane (Minrad, Inc., Bethlehem, PA, USA). Log-phase MDA-MB-231 cells were mixed with $270 \mu \mathrm{g} / \mathrm{mL}$ of control or tamoxifen rat mammary ECM at a concentration of $1.0 \times 10^{5}$ cells/ $\mu \mathrm{L}$ matrix. Of the cell/matrix mix $\left(2 \times 10^{6}\right.$ total cells), 20 $\mu \mathrm{L}$ were back-loaded into a $3 / 10 \mathrm{cc}$ insulin syringe with a 29 gauge 1/2 inch needle (BD Biosciences, San Jose, CA, USA) and injected into the fat pad of mammary gland number 4 [37]. For fibronectin experiments, MDA-MB-231 cells were mixed with incomplete $\alpha$-MEM media with or without $20 \mu \mathrm{g} / \mathrm{ml}$ fibronectin (Collaborative Biochemical, Bedford, MA, USA) just before fat pad injection, with 10 mice per group. Tumour growth was measured using calipers twice weekly. Animals were sacrificed at six weeks post tumour cell injection. Tumours were excised, weighed and final tumour volume calculated $\left(4 / 3 \pi R^{2} h\right)$. Statistical analyses were performed using the Kruskal-Wallis test and the Wilcoxon nonparametric analysis.

\section{Results \\ Characterisation of mammary and cervical tissue in tamoxifen-treated rats}

Tamoxifen is known to be an oestrogen antagonist in the mammary gland and acts to block proliferation of ER-positive epithelial cells. As expected, in comparison to control rats, the mammary epithelium in the tamoxifen-treated rats had a significant reduction in alveolar development (Figure 1a, upper panels). Morphometric analysis demonstrated that only $25 \%$ of vehicle-treated rats had mammary glands lacking well-developed alveoli, whereas $75 \%$ of mammary glands from tamoxifen-treated rats had mammary glands lacking alveoli (Figure 1a, graph). Consistent with the loss of mammary alveoli in the tamoxifen-treated rats, mammary epithelial cell proliferation, as measured by BrdU incorporation, was significantly reduced (Figure 1b, upper panels; BrdU quantification is shown in Figure 1b, lower panel). In the uterus, tamoxifen is an oestrogen agonist and one of tamoxifen's known side effects in women is an increase in uterine tumours. As previously reported by others, we found that tamoxifen-treated rats did not cycle through oestrous and the uterine and cervical tissues from these rats displayed proliferative phenotypes (Figure 1c), indicating that, as in women, tamoxifen acts as an oestrogen agonist in the rat uterus [38].

\section{Characterisation of mammary stroma composition}

To begin to address the question of whether tamoxifen alters mammary stroma, primary fibroblasts were isolated from mammary glands of control and tamoxifen-treated rats. Fibroblast cells were characterised as positive by immunohistochemistry staining for vimentin and smooth muscle actin and by lack of pan-cadherin staining (data not shown). Fibroblast motility was assessed as a functional marker of cell activity. Although inter-
Figure 1
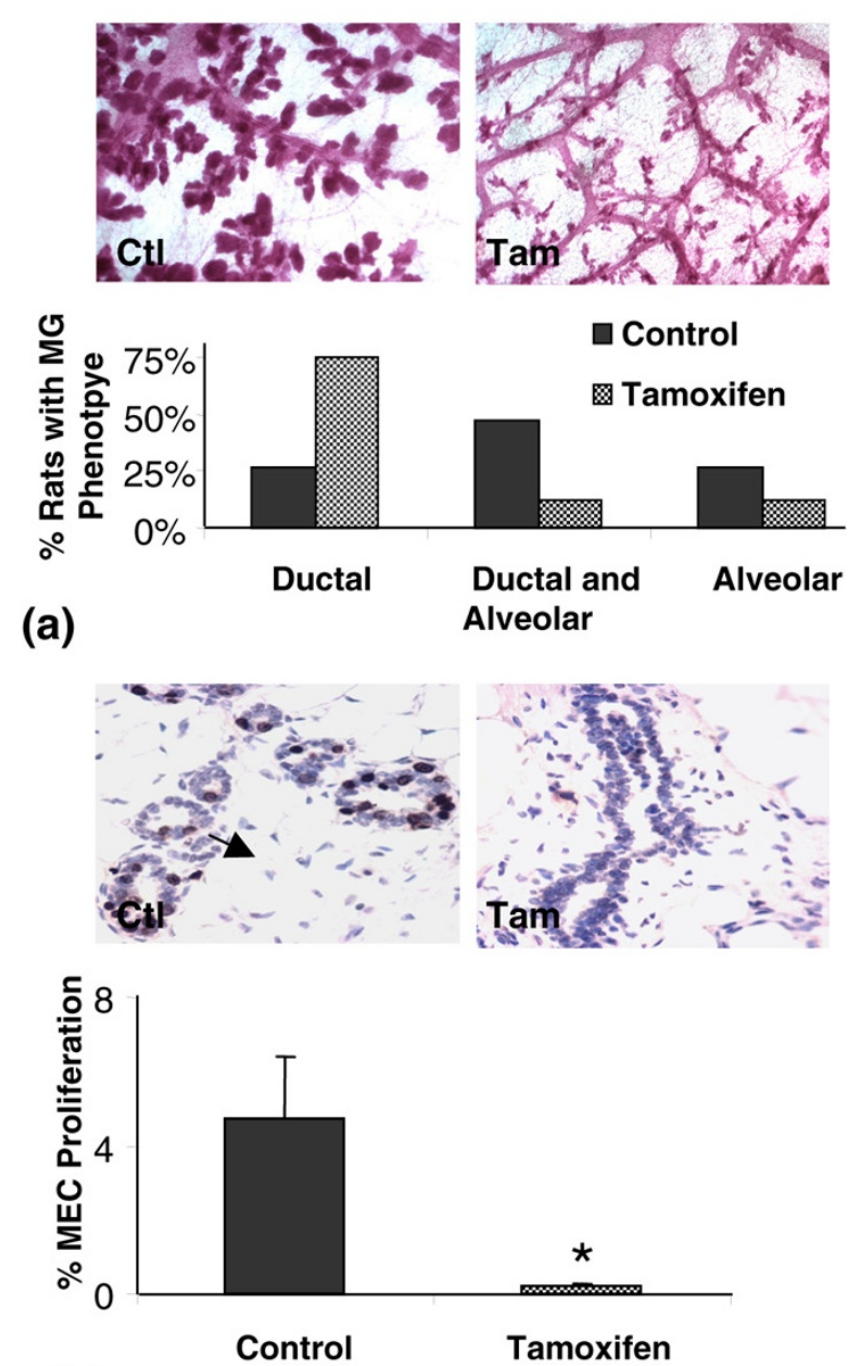

(b)

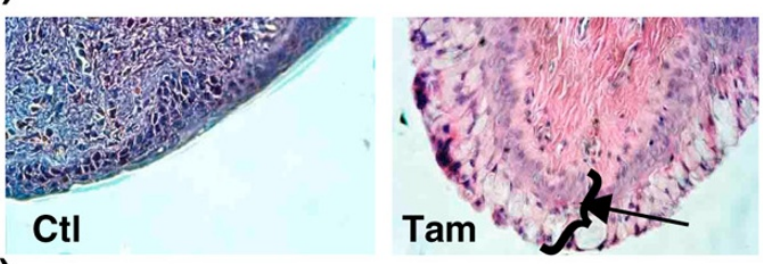

(c)

Effects of tamoxifen on proliferation of mammary and cervical epithelium. (a) upper panels: Whole mount mammary gland micrographs from control (Ctl) and tamoxifen-treated (Tam) rats showing loss of alveoli with tamoxifen treatment $40 \times$ magnification. (a) lower panel: Graph depicting percentage of rats in each group with dominant ductal, mixed or alveolar mammary gland morphology. (b) upper panels: Bromodeoxyuridine (BrdU) positive proliferating cells detected by immunohistochemistry. Arrow shows brown staining BrdU-positive cell. 400x magnification. (b) lower panel: Quantitation of proliferating mammary epithelial cells in control $(n=12)$ and tamoxifen $(n=12)$ treated rats, ${ }^{*} p<0.001$. (c) Cervical histology of control and tamoxifen-treated rats. Arrow shows thick stratum germinativum layer in tamoxifen-treated rats consistent with hormone stimulation. 
animal variation in fibroblast motility was high, overall mammary fibroblasts isolated from the tamoxifen-treated animals displayed a significant three-fold decrease in transwell filter motility compared with control mammary fibroblasts (Figure 2a).

Fibroblasts are the major producers of mammary interlobular and periductal ECM and the motility data suggested that ECM production might be similarly altered by tamoxifen treatment. To address this question, the ECM secreted by primary fibroblasts in culture and incorporated into a $3 D$ insoluble matrix was harvested and run on a 1D-gel. A prominent band of about $250 \mathrm{kD}$ was decreased in the tamoxifen group (Figure $2 \mathrm{~b}$, arrow). This band was excised and found to contain fibronectin by mass spectrometry. These data show that in vitro, mammary fibroblasts isolated from tamoxifen-treated rats are less motile and incorporate less fibronectin into the insoluble matrix than fibroblasts isolated from vehicle control rats, data consistent with tamoxifen treatment causing fibroblast quiescence.

Tissue macrophages are a stromal cell type whose presence correlates directly with breast cancer progression in women and in rodent models [39]. To determine whether tamoxifen treatment influenced the macrophage content of the mammary gland, immunohistochemistry analysis of the macrophage lysosomal marker CD68 was performed (Figure 2c, upper panels). Quantification of CD68 staining demonstrated that the CD68 signal was significantly decreased in mammary glands of tamoxifen-treated rats (Figure 2c, graph). Given that ECM proteins can function as attractants for macrophages, we next determined whether isolated ECM preparations from control and tamoxifen-treated rats differentially attract macrophages in a transwell filter assay. Using the isolated mammary matrices as chemoattractants, the motility of $\mathbf{J} 774$ cells, a mouse macrophage cell line, was suppressed by tamoxifen ECM in comparison with control ECM (Figure 3). These observations suggest that changes in mammary ECM composition with tamoxifen treatment could provide a plausible mechanism by which macrophage number is reduced in the mammary glands of tamoxifen-treated rats.

\section{Tissue matrix proteomics}

To identify prominent ECM proteins that compose the rat mammary gland stroma and which might be differentially expressed with tamoxifen treatment, ECM proteins were extracted from mammary glands of control and tamoxifentreated rats and identified by tandem mass spectrometry. Prominent ECM proteins identified included fibronectin, collagen chains $\alpha-1(\mathrm{I}), \alpha-2(\mathrm{XIV})$ and $\alpha-2(\mathrm{I})$, laminin chains $\alpha 4, \beta 1$, $\beta 2$ and $\gamma 1$, nidogen 1 and fibrillin 1 . In addition, numerous matrix proteoglycans were identified in the mammary ECM, including decorin, perlecan, lumican, biglycan, mimecan and periostin (Table 1).
Figure 2
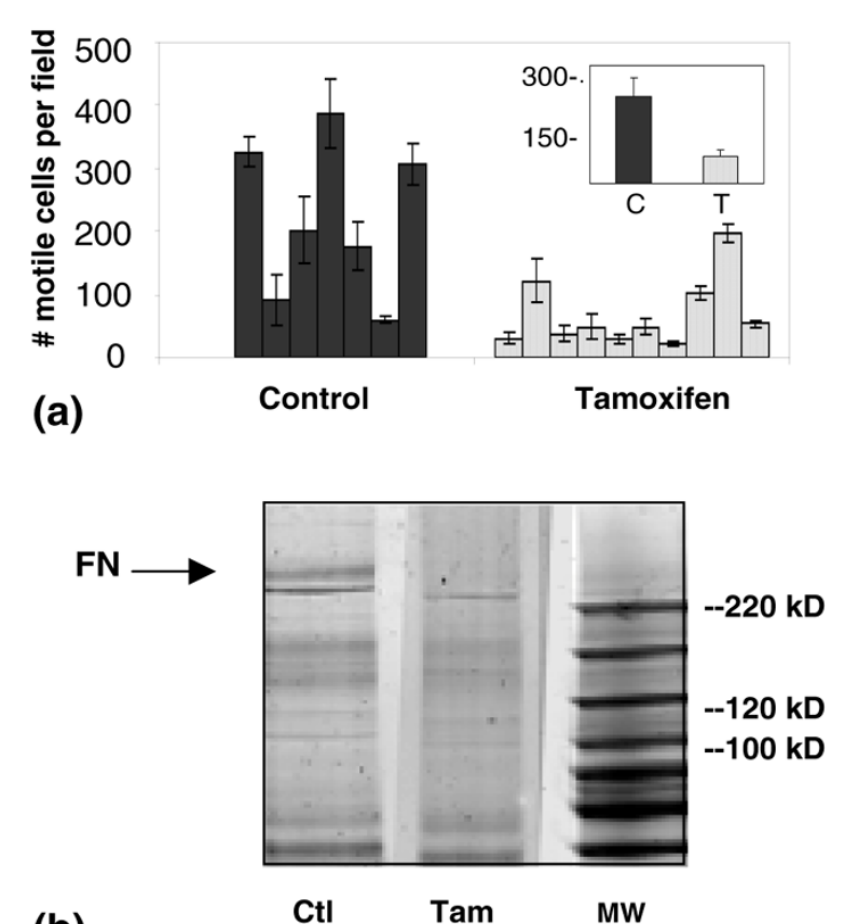

(b)

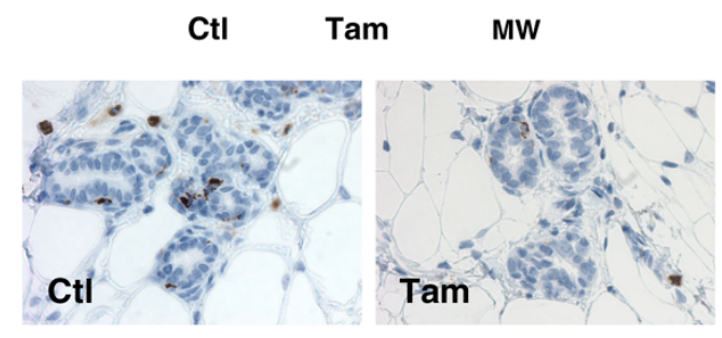

(c)

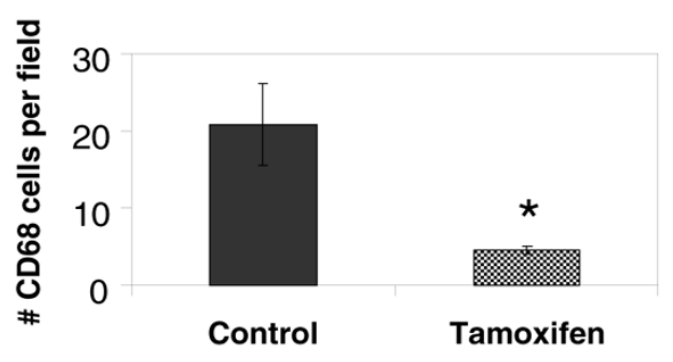

Influence of tamoxifen treatment on mammary stromal fibroblasts and macrophages. (a) Motility of primary mammary fibroblasts isolated from individual control rats ( $\mathrm{Ctl} ; n=7)$, tamoxifen-treated rats (Tam; $n=10$ ), and pooled populations (insert). (b) One-dimensional gel of extracellular matrix (ECM) proteins laid down in culture by primary mammary fibroblasts isolated from control and tamoxifen-treated rats. Arrow shows about a prominent $250 \mathrm{kD}$ band identified as containing fibronectin (FN) by mass spectrometry, which is present in control ECM and greatly reduced in tamoxifen ECM. Lane 3 depicts molecular weight (MW) marker. (c) upper panel: $5 \mu \mathrm{m}$ representative sections of mammary glands stained for CD68, a macrophage lysosomal-associated protein. $400 \times$ magnification. (c) lower panel: Quantitation of CD68 positive mammary cells in control $(n=6)$ and tamoxifen-treated $(n=6)$ rats demonstrates significantly fewer macrophages with tamoxifen treatment $\left({ }^{*} p=0.013\right)$. 
Figure 3

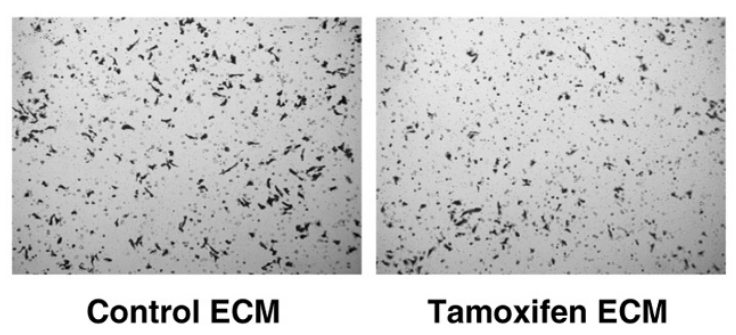

(a)

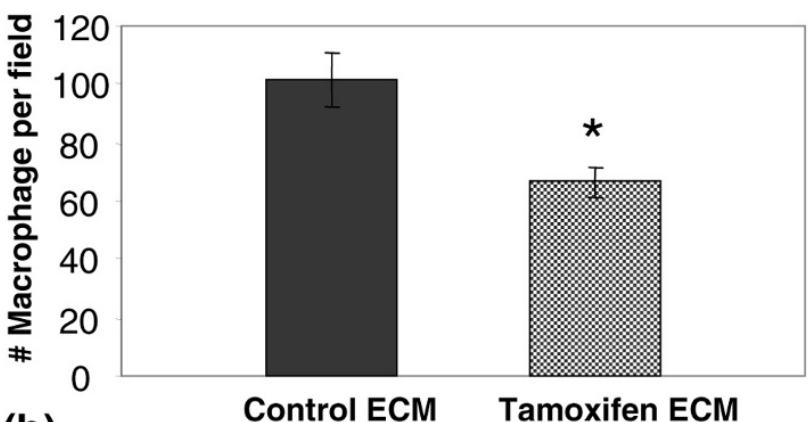

(b)

Tamoxifen extracellular matrix $(E C M)$ recruits fewer macrophages than control ECM in a transwell filter assay. (a) Photomicrographs of transwell filters showing that J774 macrophage cells are less chemotactic towards tamoxifen ECM compared with control ECM. 100x magnification. (b) Quantitation of $\mathrm{J} 774$ cell motility demonstrates significantly reduced chemotaxis towards tamoxifen ECM. ${ }^{*} p=0.003$.

To determine whether the relative abundance of the identified mammary ECM proteins differed with tamoxifen treatment, several of the ECM proteins identified by proteomics were evaluated by Western blot. Mammary tissue from tamoxifentreated rats had decreased levels of fibronectin (Figure 4a), data consistent with the in vitro fibroblast data described in Figure $2 b$. In addition, tamoxifen treatment resulted in a modest increase in the basement membrane protein laminin 1, and a decrease in total laminin 5 levels (Figure 4a). Western blot analysis revealed that tamoxifen treatment increased levels of the intra-lobular and inter-lobular ECM protein collagen 1 (Figure $4 \mathrm{~b}$, left panel). Tissue collagen deposition, as measured by Picro-sirius red staining, confirmed elevated levels of fibrillar collagen in the mammary stroma of tamoxifen-treated rats (Figure $4 \mathrm{~b}$, right panels and Table 2). Further, Western blot analyses demonstrated a generalised decrease in mammary ECM proteolysis with tamoxifen treatment, as evidenced by an increase in the ratio of high to low molecular weight species of fibronectin, laminin 1, laminin 5 and collagen 1 (Figures $4 a, b$ ).

Activity of MMP-2, an MMP found in high levels in virgin rat mammary glands and implicated in mammary ECM proteolysis, was evaluated in mammary tissue of control and tamoxifentreated rats. Total MMP-2 and active MMP-2 were found to be decreased in mammary tissue of tamoxifen-treated rats (Figure 4c, left panel). Quantitation by densitometry showed about a
Table 1

Mammary ECM proteins identified by mass spectrometry

\begin{tabular}{|c|c|}
\hline Swiss-Prot accession \# & Protein \\
\hline [Swiss-Prot:Q80X19] & Collagen alpha-1 (XIV) \\
\hline [Swiss-Prot:P02454] & Collagen alpha-1(I) \\
\hline [Swiss-Prot:P02466] & Collagen alpha-2(I) \\
\hline [Swiss-Prot:Q61554] & Fibrillin 1 \\
\hline [Swiss-Prot:Q9WVH8] & Fibulin-5 \\
\hline [Swiss-Prot:P04937] & Fibronectin \\
\hline [Swiss-Prot:P97927] & Laminin subunit alpha-4 \\
\hline [Swiss-Prot:P02469] & Laminin subunit beta- 1 \\
\hline [Swiss-Prot:P15800] & Laminin subunit beta-2 \\
\hline [Swiss-Prot:P15800] & Laminin subunit beta- 2 \\
\hline [Swiss-Prot:P02468] & Laminin subunit gamma- 1 \\
\hline [Swiss-Prot:P47853] & Biglycan \\
\hline [Swiss-Prot:0.01129] & Decorin \\
\hline [Swiss-Prot:Q9QZZ6] & Dermatopontin \\
\hline [Swiss-Prot:P51886] & Lumican \\
\hline [Swiss-Prot:Q62000] & Mimecan \\
\hline [Swiss-Prot:0.05793] & Perlecan \\
\hline [Swiss-Prot:P09650] & Mast cell protease 1 \\
\hline [Swiss-Prot:088766] & Neutrophil collagenase \\
\hline [Swiss-Prot:P10493] & Nidogen-1 \\
\hline [Swiss-Prot:Q62009] & Periostin \\
\hline [Swiss-Prot:P29457] & Serpin $\mathrm{H} 1$ precursor \\
\hline
\end{tabular}

45\% decrease in total MMP-2 (Figure 4c, upper right panel) and more than a $85 \%$ reduction in the cleaved active form of MMP-2 (Figure 4c, lower right panel). These data show that the decrease in ECM proteolysis in mammary glands of tamoxifen-treated rats correlated with concurrent decreases in MMP-2 levels and activity.

\section{In vitro functional evaluations of ECM}

As confirmed by Western blot analyses, prominent differences between control and tamoxifen mammary ECM composition were the presence of high levels of intact fibrillar collagen in mammary tissue of tamoxifen-treated rats and the presence of partially proteolysed collagen and elevated levels of fibronectin in control mammary glands. The question of whether these ECM components influence macrophage motility was evaluated next. To reconstitute the high levels of collagen 1 observed in tamoxifen ECM, $10 \mu \mathrm{g} / \mathrm{ml}$ fibrillar collagen 1 was added to control ECM. The addition of fibrillar collagen was found to suppress J774 macrophage cell motility compared with control ECM alone (Figure 5a). Conversely, the addition 

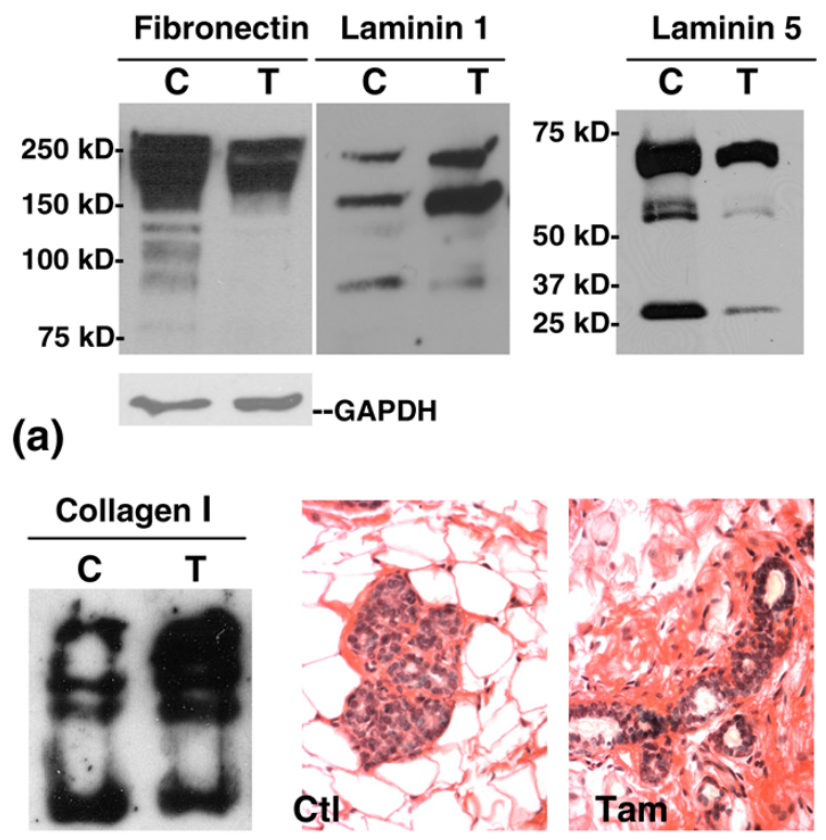

(b)

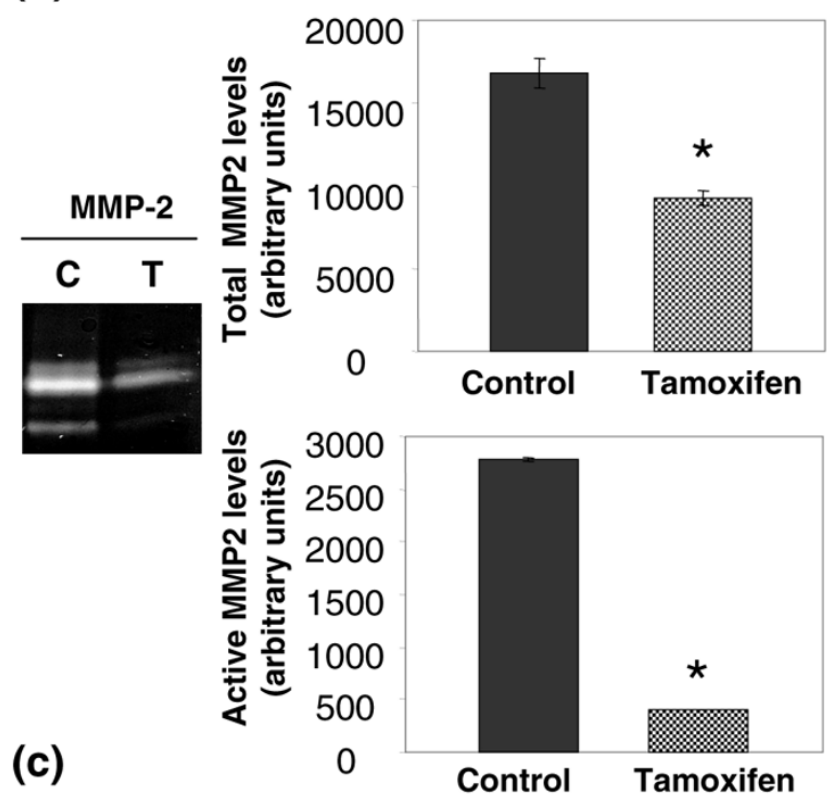

Mammary extracellular matrix (ECM) proteolysis is reduced with tamoxifen treatment. (a) Western blot analyses of fibronectin, laminin 1 and laminin 5 in mammary tissue from control and tamoxifen-treated rats, with glyceraldehyde 3-phosphate dehydrogenase (GAPDH) as loading control. (b) Fibrillar collagen detected by Western blot (left panel) and in $5 \mu \mathrm{m}$ Picro-sirius red stained mammary gland sections. (c) Matrix metalloproteinase (MMP) 2 activity detected by zymography, with total MMP-2 levels and active MMP-2 levels quantified by scanning densitometry $\left({ }^{*} p=0.005\right.$ and ${ }^{*} p<0.0001$, respectively). of $10 \mu \mathrm{g} / \mathrm{ml}$ denatured collagen to tamoxifen mammary ECM was found to stimulate macrophage motility (Figure 5b). Given that fibronectin levels were higher in control ECM than tamoxifen ECM, the effect of $10 \mu \mathrm{g} / \mathrm{ml}$ fibronectin on macrophage motility was also investigated. We found that the addition of fibronectin to tamoxifen ECM had a modest but statistically significant stimulatory influence on J774 cell motility when compared with tamoxifen ECM alone (Figure 5c). Cumulatively, these data suggest that the high level of intact collagen and reduced level of fibronectin in the mammary tissue of tamoxifen-treated rats contributes to the reduced number of macrophages observed in mammary glands of tamoxifen-treated rats.

To address whether mammary ECM isolated from tamoxifentreated rats inhibits metastatic-attributes of epithelial tumour cells in vitro, the effects of control and tamoxifen ECM on mammary tumour cell invasion, motility and haptotaxis were evaluated. In a transwell filter assay, the invasiveness of Ras transformed mammary epithelial MCF-12A cells was reduced two-fold on tamoxifen ECM compared with control ECM (Figure 6a). Differences in motility were not observed (data not shown). These functional analyses were extended to the highly metastatic human breast cancer MDA-MB-231 cells. MDAMB-231 cells had reduced motility on the tamoxifen ECM (Figure $6 \mathrm{~b}$ ), but no change in invasion (data not shown). The haptotactic properties of the isolated mammary ECM were evaluated using mammary ECM as the chemoattractant. MDAMB-231 cells displayed a three-fold reduction in haptotactic properties towards tamoxifen ECM (Figure 6c). Cumulatively, these data suggest a partial suppression of the metastatic phenotype by tamoxifen ECM.

To further characterise the effects of these ECM matrices on tumour cell behaviour, 3D cell culture assays were performed. When plated onto control ECM, MCF-12A-Ras cells displayed an aggressive phenotype characterised by disorganised structuring and invasive filapodia (Figure 7a, left panel). In contrast, when plated onto tamoxifen ECM, these same cells formed compacted smooth-surfaced multicellular clusters lacking invasive filapodia (Figure 7a, right panel). H\&E stained $4 \mu \mathrm{m}$ sections of $3 \mathrm{D}$ organoids confirmed the observation that tamoxifen ECM induced small spheroid shaped organoids (Figure 7b). Quantitative morphometric analyses of organoid size demonstrated that the average size of organoids plated onto tamoxifen ECM was 2.6-fold smaller than organoids on control ECM (Figure 7c). Even very aggressive MDA-MB-231 cells had a subtly altered 3D phenotype on the tamoxifen ECM. These cells were more clustered and cuboidal in appearance than when plated on the control ECM, indicating induction of an epithelial-like morphology (data not shown). The 3D culture data corroborate the transwell filter assay data and show that the tamoxifen ECM fails to support tumour cell motility and invasion. 
Table 2

Fibrillar collagen content of mammary glands

\begin{tabular}{|c|c|c|}
\hline Grade of collagen deposition ${ }^{a}$ & Control group & Tamoxifen group \\
\hline Grade I & $5(23 \%)$ & $0(0 \%)$ \\
\hline Grade ॥ & $12(54 \%)$ & $9(38 \%)$ \\
\hline Grade III & $5(23 \%)$ & $15(62 \%)$ \\
\hline
\end{tabular}

a Grade I glands are at least 50\% adipocyte-rich stroma and devoid of dense fibrillar collagen deposition. Grade II glands have moderate levels of dense fibrillar collagen or areas with mixed collagen densities and Grade III glands have at least $50 \%$ of glands filled with dense fibrillar collagen deposition.

To evaluate the contributions of individual ECM proteins to tumour organoid formation, reconstitution experiments were performed with fibronectin and collagen 1. The addition of high molecular weight fibronectin to tamoxifen matrix was found to consistently increase organoid size in 3D culture, but the increase in size was modest (Figure 7d). Further, an increase in local invasion was observed with fibronectin (data not shown). These data suggest that an increase in fibronectin alone does not wholly account for the aggressive phenotype displayed by MCF-12A-Ras cells plated on control ECM. Of interest, the addition of fibrillar collagen to control matrix disrupted $3 D$ organoid formation, thus the contribution of collagen to the suppressive microenvironment could not be evaluated in this model (data not shown).

\section{In vivo functional evaluation of ECM}

Based on the demonstration that tamoxifen ECM reduced the aggressive characteristics of two transformed breast cancer cell lines in multiple cell culture models, we investigated whether tamoxifen ECM could decrease tumour promotion in vivo. For this study, MDA-MB-231 cells were mixed with mammary ECM from control and tamoxifen-treated rats and injected into the inguinal fat pads of female athymic mice. By seven weeks after tumour cell injection, tumour incidence was the same between groups; however, mice injected with tumour cells plus tamoxifen ECM had tumours that were three times smaller than those injected with tumour cells mixed with control ECM (Figure 8a). To determine whether the elevated levels of fibronectin in control mammary ECM influence tumour size in this xenograft model, as suggested by the 3D organoid data, MDA-MB-231 cells were treated with $20 \mu \mathrm{g} / \mathrm{ml}$ fibronectin before mammary fat pad injection (Figure $8 \mathrm{~b}$ ). Tumour size was increased by fibronectin across all time points, however, because of a large variation in tumour size within a group, these data did not reach statistical significance.

\section{Discussion}

In this paper we characterised the tissue microenvironment associated with quiescent mammary epithelium. Mammary quiescence was induced with the anti-oestrogen tamoxifen, an agent known to suppress proliferation of normal mammary epithelium and ER-positive tumour cells [40]. In our study, in addition to the expected anti-proliferative effects of tamoxifen on mammary epithelium, tamoxifen treatment was found to induce pleiotrophic changes in the mammary microenvironment. These changes included inhibition of fibroblast motility and fibronectin incorporation into the substratum, a decrease in macrophage number, a reduction in MMP-2 activity and markedly less proteolysis of the ECM proteins fibronectin, laminin 1 , laminin 5 and collagen 1 . This response of the mammary stroma to tamoxifen treatment provides further evidence for the hypothesis that dynamic and reciprocal interactions occur between epithelium and stroma, and that these interactions dictate epithelial cell function [4,41]. Further, this study demonstrates the plasticity of the adult mammary stroma, which has significant implications for stromal-targeted therapeutics.

ECM proteins represent a dominant component of the stromal microenvironment and ECM composition, organisation, cross linking and turnover are attributes determined primarily by stromal cells. Thus, ECM composition can be considered as a read-out of changes in stromal cell function. As such, we evaluated whether tamoxifen treatment altered functional attributes of mammary ECM. Matrix proteins isolated from tamoxifen-treated rats were found to suppress macrophage and breast tumour cell motility, tumour cell invasion and haptotaxis in transwell filter assays, to significantly reduce the size of tumour cell organoids in 3D culture, and to inhibit tumour progression in a xenograft model of breast cancer. Mammary ECM isolated from control rats did not have these attributes. These data indicate that tamoxifen modifies the mammary microenvironment in a manner consistent with tumour suppression, which may shed light on tumour dormancy, the latent phase that occurs between treatment and disease progression. Relapse from dormancy can occur after prolonged periods of disease-free survival, and is a particular problem in breast cancer $[20,21]$.

Using tamoxifen-induced mammary quiescence as an in vivo model for tumour dormancy, we identified several candidate stromal mediators of tumour quiescence. We observed a decrease in total fibronectin in mammary tissue with tamoxifen treatment and reduced fibronectin secretion by fibroblasts isolated from mammary glands of tamoxifen-treated rats. In rodent models, fibronectin mRNA expression is upregulated during periods of high proliferation such as puberty and pregnancy, 
Figure 5
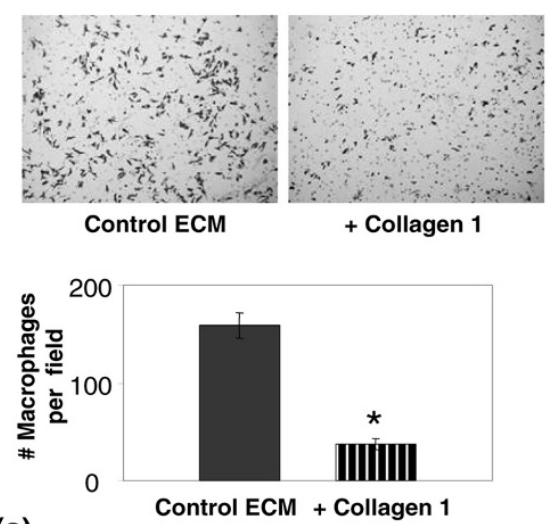

(a)
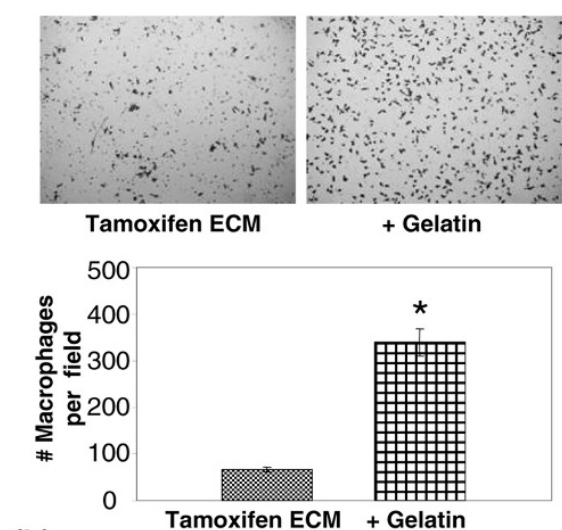

(b)

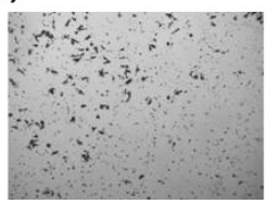

Tamoxifen ECM

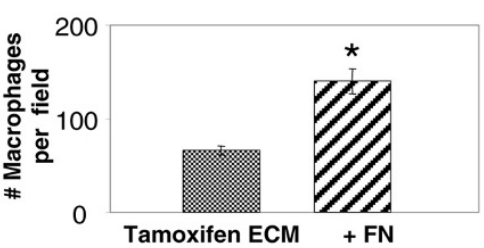

(c)

Macrophage chemotaxis is influenced by the denatured state of collagen 1 and fibronectin (FN) levels. (a) upper panel: Photomicrograph of transwell filter showing inhibition of J774 cell motility when $10 \mu \mathrm{g} / \mathrm{ml}$ fibrillar collagen 1 is added to control extracellular matrix (ECM) and used as chemoattractant. 100x magnification. (a) lower panel: Quantitation of data demonstrates significantly reduced chemotaxis towards collagen 1. ${ }^{*} p<0.0001$. (b) upper panel: Photomicrograph showing that $10 \mu \mathrm{g} / \mathrm{ml}$ denatured collagen (gelatin) added to tamoxifen ECM as chemoattractant increases $\mathrm{J} 774$ macrophage cell motility. 100x magnification. (b) lower panel: Quantitation of data demonstrates significantly increased chemotaxis towards denatured collagen, ${ }^{*} p<0.0001$. (c) upper panel: Photomicrograph showing that $20 \mu \mathrm{g} / \mathrm{ml} F N$ added to tamoxifen ECM increases J774 cell motility. $100 \times$ magnification. (c) lower panel: quantitation of data demonstrates significantly increased chemotaxis towards FN. ${ }^{*} p=0.0004$.
Figure 6
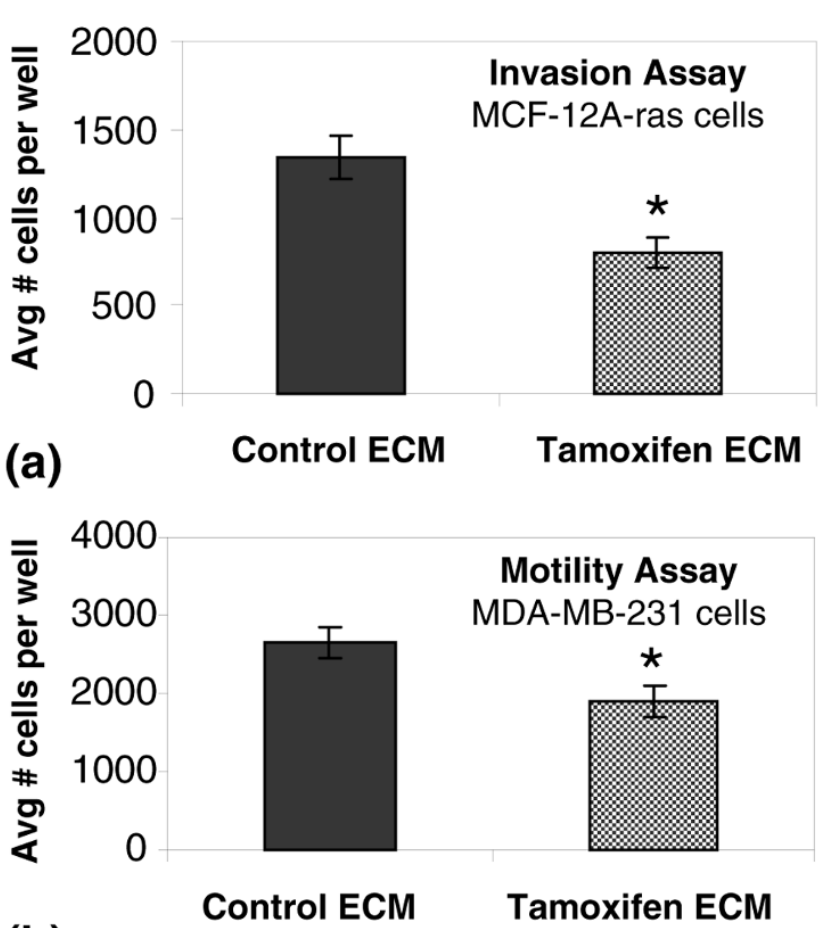

(b)

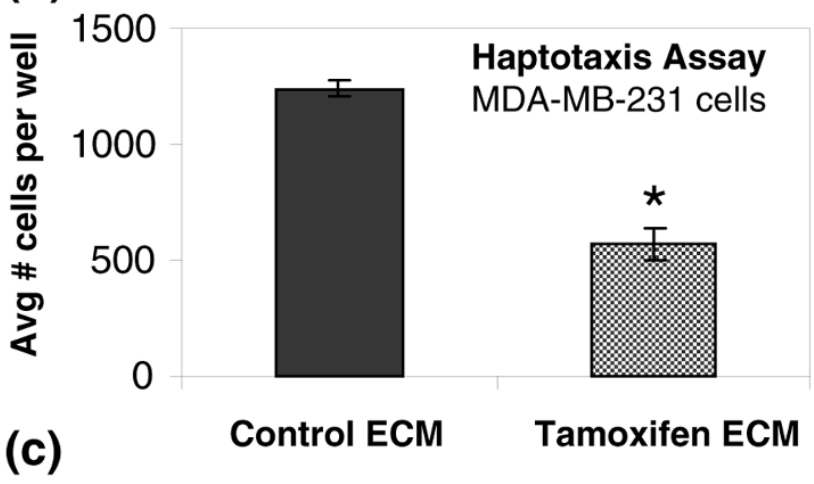

Mammary extracellular matrix (ECM) from tamoxifen-treated rats suppresses metastatic attributes of transformed mammary epithelial cells in comparison with ECM from control rats. (a) MCF-12A-Ras cell invasion through $8 \mu \mathrm{m}$ transwell filter pores occluded with $200 \mu \mathrm{g} / \mathrm{ml}$ mammary ECM was suppressed in response to tamoxifen in comparison with control ECM. *p < 0.024. (b) Motility of MDA-MB-231 cells was inhibited in response to filters coated with $10 \mu \mathrm{g} / \mathrm{ml}$ tamoxifen ECM compared with control ECM. * $p<0.005$. (c) Using mammary matrices as chemoattractant, MDA-MB-231 cells were less motile towards tamoxifen ECM. ${ }^{*} p<8.3 E-5$.

and suppressed during gland involution following weaning $[5,6,42]$. Further, the addition of fibronectin to Matrigel in a 3D culture model stimulated mammary epithelial cell proliferation and increased acinar size [43]. These observations implicate fibronectin as a key ECM mediator of mammary epithelial cell proliferation in vivo. Further, under adverse conditions such as hypoxia, fibronectin can act as a pro-survival protein due to upregulation of $\alpha 5 \beta 1$ integrin. For example, oncogenic activa- 
Figure 7

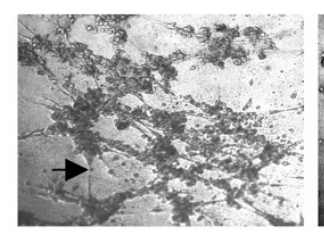

(a)

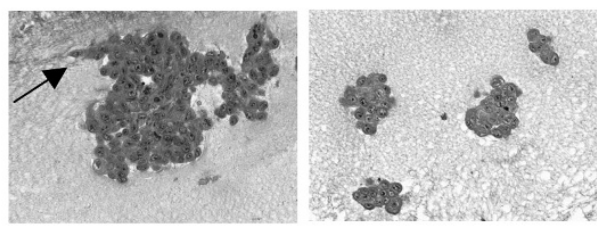

(b)

Control ECM

Tamoxifen ECM

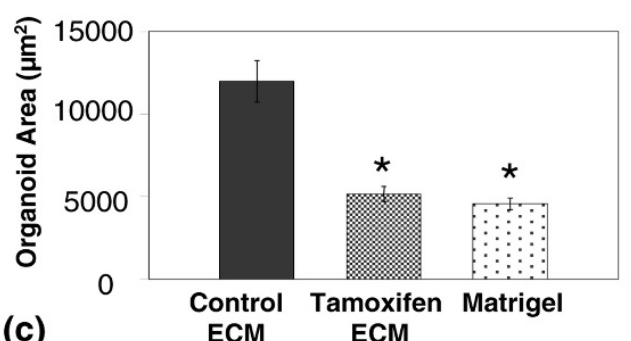

(c)

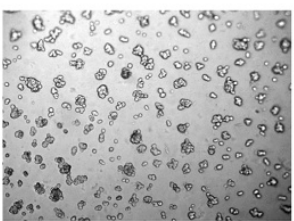

Tamoxifen ECM

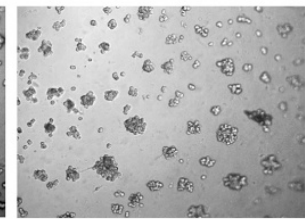

$+\mathrm{FN}$

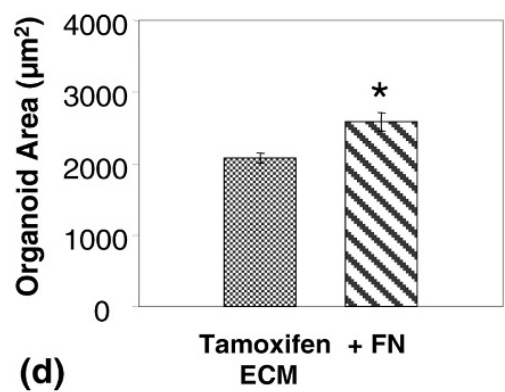

Mammary extracellular matrix (ECM) isolated from tamoxifen-treated rats inhibits tumour cell invasion in 3-dimensional (3D) culture. (a) Whole-mount 3D organoid images of MCF12A-Ras cells plated onto control and tamoxifen derived mammary ECM. Left panel arrow depicts commonly occurring tumour cell filapodia invading control ECM. Right panel shows small compacted 3D organoids that formed on mammary ECM isolated from tamoxifen treated rats. (b) $5 \mu \mathrm{m}$ H\&E-stained sections of organoids on control and tamoxifen ECM 200x magnification. Arrow depicts locally invasive tumour cells present in control ECM cultures. (c) Quantitation of organoid size that developed on control mammary ECM, tamoxifen ECM and Matrigel. Tamoxifen and Matrigel organoid size do not differ, but are different from control ECM organoid size. ${ }^{*} p<0.0001$. (d) upper panel: The addition of $20 \mu \mathrm{g} / \mathrm{ml}$ fibronectin (FN) to tamoxifen ECM increased organoid size by about $20 \%$. (d) lower panel: Quantitation of organoid size. ${ }^{*} p<0.002$.
Figure 8
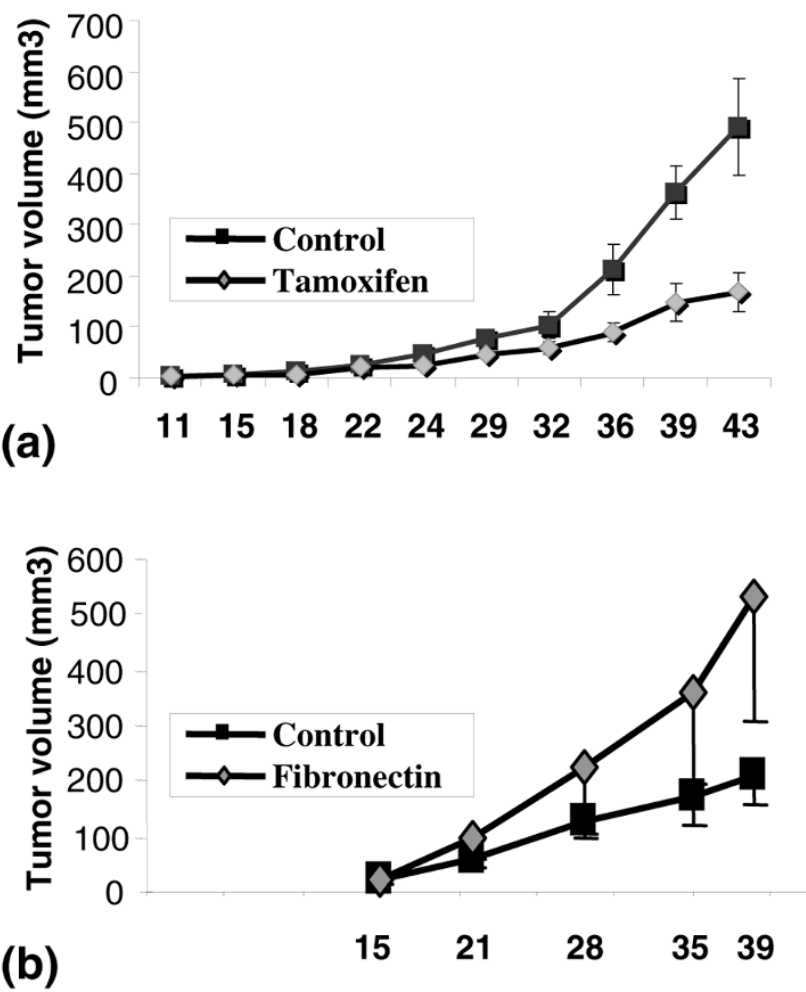

Mammary extracellular matrix (ECM) isolated from tamoxifen-treated rats inhibits tumours in an orthotopic xenograft model. (a) MDA-MB231 tumour cells mixed with tamoxifen ECM formed smaller tumours than when mixed with control ECM. $n=20$ per group. (b) MDA-MB231 tumour cells mixed with $20 \mu \mathrm{g} / \mathrm{ml}$ fibronectin had a trend towards larger tumour size, consistent with fibronectin contributing to larger tumour size observed with control ECM. $n=10$ per group.

tion of the receptor tyrosine kinase ERBB2 contributes to tumour cell resistance to hypoxia by inducing the $\alpha 5 \beta 1$ integrin fibronectin receptor, which increases cell adhesion and survival [44]. In a pancreatic tumour model, fibronectin interaction with $\alpha 5 \beta 3$ caused transactivation of the insulin-like growth factor-1 receptor and increased tumour cell survival [45]. Additional roles for fibronectin in promoting tumour cells are suggested by data demonstrating that proteolytic processing of fibronectin induces breast tumour cell motility, invasion and activation of MMP-9 $[15,16]$.

Fibronectin has also been implicated directly in the induction and regulation of dormancy. In cell culture studies, downregulation of $\beta 1$ integrin induced invasive fibroblast-like breast tumour cells to revert to polarised cells capable of contributing to acinar-like epithelium in vitro [24]. In a head and neck carcinoma model, $\alpha 5 \beta 1$ integrin engagement with fibronectin matrix promoted tumour cell proliferation, whereas disruption of this ECM interaction suppressed extracellular signal-regulated kinase activation and induced a dormant-like state 
$[46,47]$. In another 3D model of dormancy, using several breast cancer cell lines that exhibit dormancy in lungs of xenografted mice, the transition from quiescence to proliferation was found to be dependent on fibronectin production, signaling through $\beta 1$ integrin, cytoskeletal reorganisation and the formation of actin stress fibers [48]. Thus, the reconstitution experiments reported here, where exogenous fibronectin partially reverted the protective effect of tamoxifen ECM on tumour cells in vitro and in a xenograft model of breast cancer, implicate reduced levels of fibronectin as being a signal from the microenvironment that contributes to tumour cell suppression. Our data indicate that this important growth promoting ECM signal is negatively regulated by tamoxifen.

An additional prominent difference between tamoxifen-treated and control rat mammary stroma was the reduction in matrix proteolysis in the tamoxifen group. Proteolytic cleavage of ECM proteins, which can unmask cryptic sites and release fragments with bioactivity distinct from the parent molecule, have important roles in immune modulation and cancer progression [49-51]. For example, in vitro collagen 1, fibronectin, laminin and entactin derived peptides exhibit chemotactic activity for inflammatory cells $[49,52]$. These previously published studies are consistent with our data showing macrophage number was reduced in tamoxifen-treated mammary glands, in vitro macrophage motility suppressed by tamoxifen matrix and macrophage motility stimulated by the addition of exogenous fibronectin and denatured collagen; ECM proteins prominent in control mammary matrix. The observation that tamoxifen treatment reduces mammary macrophage number is intriguing because macrophages have been demonstrated to be required for the rapid proliferative phase that occurs with pubertal gland expansion [53]. In addition, macrophages are implicated in numerous events associated with cancer progression, including enhanced breast tumour cell motility, increased ECM remodeling, and blood vessel development [53-55]. In women, breast cancers with a macrophage infiltrate have a poorer prognosis, supporting the hypothesis that macrophages are promoters of breast cancer [56]. Our data extends these observations to suggest that inhibition of ECM remodeling and macrophage recruitment are components of the quiescent/dormant mammary microenvironment.

Tamoxifen treatment was also associated with an apparent inhibition of LN5 $\gamma 2$ chain cleavage because the level of about a $25 \mathrm{kD}$ proteolytic fragment of $\gamma 2$ was reduced with tamoxifen treatment. It has previously been demonstrated that membrane type 1 (MT1)-MMP cleaves the rat $\gamma 2$ chain to release about a $30 \mathrm{kD}$ fragment containing EGF-like repeats [57]. This LN5 fragment binds to EGF receptors and stimulates breast tumour cell scattering and migration. A similar proteolytic cleavage site and bioactive $\gamma 2$ fragment has been identified in human LN5 [51]. The apparent ability of tamoxifen to reduce the amount of this pro-tumourigenic LN5 fragment is additional support for suppression of ECM turnover being important for gland quiescence.

Collagen type 1 chains $\alpha-1(I)$ and $\alpha-2(I)$, components of fibrillar collagen, were identified in the isolated ECM by proteomic analysis. Further, fibrillar collagen, detected in tissue sections by Sirius red F3B staining, was observed at higher levels in tamoxifen-treated glands than in control glands. This observation is somewhat perplexing because high levels of fibrillar collagen are a component of reactive stroma around tumours and, in vivo, breast cancer tumour cells have been observed to migrate along collagen fibrils during metastasis [58,59]. As with fibronectin and laminin, mammary collagen 1 cleavage was decreased with tamoxifen treatment (Figure 4b). Thus, slower matrix turnover may account for the high levels of fibrillar collagen observed with tamoxifen, but this remains to be determined. Collagen turnover has been correlated with a tumour permissive stroma, whereas inhibition of collagen turnover has been shown to delay mammary tumour progression and metastasis [60,61]. Using human melanoma cells, cellcycle arrest was induced by fibrillar collagen [62]. The question of whether mammary epithelial cell contact with fibrillar collagen similarly restricts proliferation has not been evaluated.

Our proteomic analysis identified several proteoglycans present in mammary ECM including decorin, lumican, perlecan, biglycan, mimecan and periostin. These proteoglycans have roles in collagen assembly, fibrosis, wound healing and cancer [63]. The roles of these ECM proteins in normal and transformed mammary tissue are largely unknown, and these proteins remain interesting candidates for further study.

The pleiotrophic response of the mammary stroma to tamoxifen treatment suggests that tamoxifen influences the expression of a master regulator of stromal function. Research by other groups indicates that tumour growth factor (TGF) $\beta$, which acts on fibroblasts, immune and endothelial cells, in addition to epithelial cells, is a candidate regulator. In tamoxifen-sensitive breast tumour cells, growth inhibition has been shown to be mediated by activation of TGF $\beta$ [64]. Further, the ability of tumour cells to upregulate TGF $\beta$ and its receptor T $\beta R$ II predict drug sensitivity [28]. The question of whether TGF $\beta$ mediates the response to tamoxifen in normal glandular epithelium, as reported here, is unknown. Another question unresolved by our study is whether the response of the stroma to tamoxifen is direct or indirect. ER-positive mammary fibroblasts have been described and, in our study, a small percentage of the mammary fibroblasts were found by immunohistochemistry to be $\mathrm{ER} \alpha$ or $\mathrm{ER} \beta$ positive (data not shown). Direct evidence for breast tumour fibroblasts modulating tamoxifen sensitivity in tumour cells has recently been reported [65]. In that study, using a 3D co-culture model, MCF-7 cells mixed with Ero-positive/progesterone receptor (PR)-positive fibroblasts were growth inhibited by tamoxifen, whereas MCF- 
7 cells co-cultured with Ero-negative/PR-negative fibroblasts exhibited decreased tamoxifen sensitivity [65]. That study is highly supportive of tumour fibroblasts being direct targets of tamoxifen.

\section{Conclusions}

In summary, in the normal mammary gland, a homeostatic balance appears to occur between ECM synthesis and turnover resulting in the regulated release of bioactive ECM fragments. One potential function of these ECM fragments is the recruitment of macrophages for immune surveillance. Based on our in vitro and in vivo studies, we find that the ECM turnover and macrophage recruitment associated with the normal mammary microenvironment is supportive of tumour cell progression. Tamoxifen treatment was found to shift this balance toward suppression of fibronectin synthesis, reduced ECM turnover, accumulation of fibrillar collagen and reduced macrophage infiltrate, resulting in a microenvironment that was suppressive to breast tumour cells. Cumulatively, these data implicate suppression of ECM turnover as being critical for a quiescent mammary microenvironment and possibly tumour dormancy. Also, these data suggest the compelling possibility that the microenvironment may be part of the response to a variety of physiological and drug interventions that are chemoprotective, and that by characterising stromal changes induced by these agents, important insight into tumour cell dormancy can be obtained.

\section{Competing interests}

The authors declare that they have no competing interests.

\section{Authors' contributions}

$\mathrm{RH}$ participated in study design, animal husbandry, performed most cell culture experiments and mammary ECM isolation. $\mathrm{RH}$ was also involved in statistical analyses, drafting of the manuscript and production of figures. OM performed all macrophage experiments, 3D organoid quantitation, ECM reconstitution experiments and production of figures. SM was involved in study design, animal husbandry, primary fibroblast isolation and motility assays, and mammary ECM isolation. $\mathrm{KCH}$ was responsible for mass spectrometry studies and mining of mass spectrometry data. $\mathrm{KJH}$ was responsible for animal husbandry, Western blot and zymography analyses. TL performed the fibronectin xenograft study. SL developed the automated morphometric quantitation system required for the 3D assays. SW developed the software required for the automated quantisation of $3 D$ organoids and performed subsequent analyses and statistical tests. PS was responsible for study conception, design, data interpretation and manuscript preparation.

\section{Acknowledgements}

The authors would like to thank Pat Bell for expert histological assistance and Lauren Kimele for assistance with mass spectrometry. We are grateful to Rafe Nemenoff for critical review of the manuscript. This work was supported by grants from the Department of Defense \#
BC051532, the American Cancer Society, ACS IRG \#57-001-47 and the Butcher Family Foundation to PS, and NIH grant T32CA079446-08 to TL.

\section{References}

1. Bissell MJ, Labarge MA: Context, tissue plasticity, and cancer: are tumor stem cells also regulated by the microenvironment? Cancer Cell 2005, 7:17-23.

2. Bissell MJ, Barcellos-Hoff $\mathrm{MH}$ : The influence of extracellular matrix on gene expression: is structure the message? J Cell Sci Supp/ 1987, 8:327-343.

3. Kalluri R, Zeisberg M: Fibroblasts in cancer. Nat Rev Cancer 2006, 6:392-401.

4. Spencer VA, Xu R, Bissell MJ: Extracellular matrix, nuclear and chromatin structure, and gene expression in normal tissues and malignant tumors: a work in progress. Adv Cancer Res 2007, 97:275-294.

5. Schedin P, Mitrenga T, McDaniel S, Kaeck M: Mammary ECM composition and function are altered by reproductive state. Mol Carcinog 2004, 41:207-220.

6. Woodward TL, Mienaltowski AS, Modi RR, Bennett JM, Haslam SZ: Fibronectin and the alpha(5)beta(1) integrin are under developmental and ovarian steroid regulation in the normal mouse mammary gland. Endocrinology 2001, 142:3214-3222.

7. Xie J, Haslam SZ: Extracellular matrix regulates ovarian hormone-dependent proliferation of mouse mammary epithelial cells. Endocrinology 1997, 138:2466-2473.

8. Egeblad M, Littlepage LE, Werb Z: The fibroblastic coconspirator in cancer progression. Cold Spring Harb Symp Quant Biol 2005, 70:383-388.

9. Mueller MM, Fusenig NE: Friends or foes - bipolar effects of the tumour stroma in cancer. Nat Rev 2004, 4:839-849.

10. Tuxhorn JA, Ayala GE, Smith MJ, Smith VC, Dang TD, Rowley DR: Reactive stroma in human prostate cancer: induction of myofibroblast phenotype and extracellular matrix remodeling. Clin Cancer Res 2002, 8:2912-2923.

11. Barcellos-Hoff MH, Aggeler J, Ram TG, Bissell MJ: Functional differentiation and alveolar morphogenesis of primary mammary cultures on reconstituted basement membrane. Development 1989, 105:223-235.

12. De Wever $\mathrm{O}$, Mareel $\mathrm{M}$ : Role of tissue stroma in cancer cell invasion. J Pathol 2003, 200:429-447.

13. Pupa SM, Menard S, Forti S, Tagliabue E: New insights into the role of extracellular matrix during tumor onset and progression. J Cell Physiol 2002, 192:259-267.

14. Tlsty TD: Stromal cells can contribute oncogenic signals. Semin Cancer Biol 2001, 11:97-104.

15. Bemis LT, Schedin P: Reproductive state of rat mammary gland stroma modulates human breast cancer cell migration and invasion. Cancer Res 2000, 60:3414-3418.

16. Schedin $P$, Strange $R$, Mitrenga T, Wolfe $P$, Kaeck M: Fibronectin fragments induce MMP activity in mouse mammary epithelial cells: evidence for a role in mammary tissue remodeling. $J$ Cell Sci 2000, 113:795-806.

17. McDaniel SM, Rumer KK, Biroc SL, Metz RP, Singh M, Porter W, Schedin P: Remodeling of the mammary microenvironment after lactation promotes breast tumor cell metastasis. $\mathrm{Am} J$ Pathol 2006, 168:608-620.

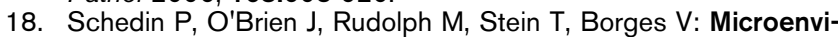
ronment of the involuting mammary gland mediates mammary cancer progression. J Mammary Gland Biol Neoplasia 2007, 12:71-82.

19. Naumov GN, MacDonald IC, Weinmeister PM, Kerkvliet N, Nadkarni KV, Wilson SM, Morris VL, Groom AC, Chambers AF: Persistence of solitary mammary carcinoma cells in a secondary site: a possible contributor to dormancy. Cancer Res 2002, 62:2162-2168.

20. Vessella RL, Pantel K, Mohla S: Tumor cell dormancy: an $\mathrm{NCl}$ workshop report. Cancer Biol Ther 2007, 6:1496-1504.

21. Brackstone M, Townson JL, Chambers AF: Tumour dormancy in breast cancer: an update. Breast Cancer Res 2007, 9:208.

22. Folkman J, Kalluri R: Cancer without disease. Nature 2004, 427:787. 
23. Pierce GB, Speers WC: Tumors as caricatures of the process of tissue renewal: prospects for therapy by directing differentiation. Cancer Res 1988, 48:1996-2004.

24. Weaver VM, Petersen OW, Wang F, Larabell CA, Briand P, Damsky C, Bissell MJ: Reversion of the malignant phenotype of human breast cells in three-dimensional culture and in vivo by integrin blocking antibodies. J Cell Biol 1997, 137:231-245.

25. Kenny PA, Bissell MJ: Tumor reversion: correction of malignant behavior by microenvironmental cues. Int J Cancer 2003, 107:688-695.

26. Deng G, Lu Y, Zlotnikov G, Thor AD, Smith HS: Loss of heterozygosity in normal tissue adjacent to breast carcinomas. Science 1996, 274:2057-2059.

27. Smith R: A review of selective estrogen receptor modulators and national surgical adjuvant breast and bowl project clinical trials. Semin Oncol 2003, 30(5 Suppl 16):4-13.

28. Buck MB, Coller JK, Murdter TE, Eichelbaum M, Knabbe C: TGFbeta2 and TbetaRII are valid molecular biomarkers for the antiproliferative effects of tamoxifen and tamoxifen metabolites in breast cancer cells. Breast Cancer Res Treat 2008, 107:15-24.

29. Schedin $\mathrm{P}$, Mitrenga $T$, Kaeck M: Estrous cycle regulation of mammary epithelial cell proliferation, differentiation, and death in the Sprague-Dawley rat: a model for investigating the role of estrous cycling in mammary carcinogenesis. J Mammary Gland Biol Neoplasia 2000, 5:211-225.

30. Allinen M, Beroukhim R, Cai L, Brennan C, Lahti-Domenici J, Huang H, Porter D, Hu M, Chin L, Richardson A, Schnitt S, Sellers WR, Polyak K: Molecular characterization of the tumor microenvironment in breast cancer. Cancer Cell 2004, 6:17-32.

31. Cukierman E, ed.: Preparation of extracellular matrices produced by cultured fibroblasts. New York: Wiley and Sons; 2002.

32. McDaniel SM, O'Neill C, Metz RP, Tarbutton E, Stacewicz-Sapuntzakis $\mathrm{M}$, Heimendinger J, Wolfe $\mathrm{P}$, Thompson $\mathrm{H}$, Schedin $\mathrm{P}$ : Whole-food sources of vitamin A more effectively inhibit female rat sexual maturation, mammary gland development, and mammary carcinogenesis than retinyl palmitate. J Nutr 2007, 137:1415-1422.

33. Lopez-De Leon A, Rojkind M: A simple micromethod for collagen and total protein determination in formalin-fixed paraffinembedded sections. J Histochem Cytochem 1985, 33:737-743.

34. Sather S, Kenyon KD, Lefkowitz JB, Liang X, Varnum BC, Henson PM, Graham DK: A soluble form of the Mer receptor tyrosine kinase inhibits macrophage clearance of apoptotic cells and platelet aggregation. Blood 2007, 109:1026-1033.

35. Paine TM, Soule HD, Pauley RJ, Dawson PJ: Characterization of epithelial phenotypes in mortal and immortal human breast cells. Int J Cancer 1992, 50:463-473.

36. Schedin PJ, Eckel-Mahan KL, McDaniel SM, Prescott JD, Brodsky KS, Tentler JJ, Gutierrez-Hartmann A: ESX induces transformation and functional epithelial to mesenchymal transition in MCF-12A mammary epithelial cells. Oncogene 2004, 23:1766-1779.

37. Mehta RR, Graves JM, Hart GD, Shilkaitis A, Das Gupta TK: Growth and metastasis of human breast carcinomas with Matrigel in athymic mice. Breast Cancer Res Treat 1993, 25:65-71.

38. Carthew P, Edwards RE, Nolan BM, Martin EA, Smith LL: Tamoxifen associated uterine pathology in rodents: relevance to women. Carcinogenesis 1996, 17:1577-1582.

39. Pollard JW: Tumour-educated macrophages promote tumour progression and metastasis. Nat Rev Cancer 2004, 4:71-78.

40. Jordan VC: Third annual William L. McGuire Memorial Lecture. "Studies on the estrogen receptor in breast cancer -20 years as a target for the treatment and prevention of cancer". Breast Cancer Res Treat 1995, 36:267-285.

41. Nelson CM, Bissell MJ: Modeling dynamic reciprocity: engineering three-dimensional culture models of breast architecture, function, and neoplastic transformation. Semin Cancer Biol 2005, 15:342-352

42. Haslam SZ, Woodward TL: Reciprocal regulation of extracellular matrix proteins and ovarian steroid activity in the mammary gland. Breast Cancer Res 2001, 3:365-372.

43. Williams CM, Engler AJ, Slone RD, Galante LL, Schwarzbauer JE: Fibronectin expression modulates mammary epithelial cell proliferation during acinar differentiation. Cancer Res 2008, 68:3185-3192.

44. Spangenberg C, Lausch EU, Trost TM, Prawitt D, May A, Keppler R, Fees SA, Reutzel D, Bell C, Schmitt S, Schiffer IB, Weber A Brenner W, Hermes M, Sahin U, Türeci O, Koelbl H, Hengstler JG, Zabel BU: ERBB2-mediated transcriptional up-regulation of the alpha5beta1 integrin fibronectin receptor promotes tumor cell survival under adverse conditions. Cancer Res 2006, 66:3715-3725.

45. Edderkaoui M, Hong P, Lee JK, Pandol SJ, Gukovskaya AS: Insulin-like growth factor-I receptor mediates the prosurviva effect of fibronectin. J Biol Chem 2007, 282:26646-26655.

46. Aguirre-Ghiso JA, Liu D, Mignatti A, Kovalski K, Ossowski L: Urokinase receptor and fibronectin regulate the ERK(MAPK) to p38(MAPK) activity ratios that determine carcinoma cell proliferation or dormancy in vivo. Mol Biol Cell 2001, 12:863-879.

47. Chaurasia P, Aguirre-Ghiso JA, Liang OD, Gardsvoll H, Ploug M, Ossowski L: A region in urokinase plasminogen receptor domain III controlling a functional association with alpha5beta1 integrin and tumor growth. J Biol Chem 2006, 281:14852-14863.

48. Barkan D, Kleinman $\mathrm{H}$, Simmons JL, Asmussen $\mathrm{H}$, Kamaraju AK, Hoenorhoff MJ, Liu ZY, Costes SV, Cho EH, Lockett S, Khanna C, Chambers AF, Green JE: Inhibition of metastatic outgrowth from single dormant tumor cells by targeting the cytoskeleton. Cancer Res 2008, 68:6241-6250.

49. Adair-Kirk TL, Senior RM: Fragments of extracellular matrix as mediators of inflammation. Int J Biochem Cell Biol 2008, 40:1101-1110.

50. Schenk S, Quaranta V: Tales from the crypt[ic] sites of the extracellular matrix. Trends Cell Bio/ 2003, 13:366-375.

51. Koshikawa N, Minegishi T, Sharabi A, Quaranta V, Seiki M: Membrane-type matrix metalloproteinase-1 (MT1-MMP) is a processing enzyme for human laminin gamma 2 chain. $J$ Biol Chem 2005, 280:88-93.

52. Adair-Kirk TL, Atkinson JJ, Broekelmann TJ, Doi M, Tryggvason $\mathrm{K}$, Miner JH, Mecham RP, Senior RM: A site on laminin alpha 5 , AQARSAASKVKVSMKF, induces inflammatory cell production of matrix metalloproteinase-9 and chemotaxis. I Immunol 2003, 171:398-406.

53. Pollard JW, Hennighausen L: Colony stimulating factor 1 is required for mammary gland development during pregnancy. Proc Natl Acad Sci USA 1994, 91:9312-9316.

54. Condeelis J, Pollard JW: Macrophages: obligate partners for tumor cell migration, invasion, and metastasis. Cell 2006 124:263-266.

55. Lin EY, Nguyen AV, Russell RG, Pollard JW: Colony-stimulating factor 1 promotes progression of mammary tumors to malignancy. J Exp Med 2001, 193:727-740.

56. Lin EY, Pollard JW: Macrophages: modulators of breast cancer progression. Novartis Foundation Symposium 2004 256:158-168. discussion 168-172, 259-169.

57. Schenk S, Hintermann E, Bilban M, Koshikawa N, Hojilla C, Khokha R, Quaranta V: Binding to EGF receptor of a laminin-5 EGF-like fragment liberated during MMP-dependent mammary gland involution. J Cell Biol 2003, 161:197-209.

58. Wang W, Wyckoff JB, Frohlich VC, Oleynikov $Y$, Hüttelmaier $S$, Zavadil J, Cermak L, Bottinger EP, Singer RH, White JG, Segall JE, Condeelis JS: Single cell behavior in metastatic primary mammary tumors correlated with gene expression patterns revealed by molecular profiling. Cancer Res 2002, 62:6278-6288.

59. Wyckoff JB, Jones JG, Condeelis JS, Segall JE: A critical step in metastasis: in vivo analysis of intravasation at the primary tumor. Cancer Res 2000, 60:2504-2511.

60. Curino AC, Engelholm LH, Yamada SS, Holmbeck K, Lund LR, Molinolo AA, Behrendt N, Nielsen BS, Bugge TH: Intracellular collagen degradation mediated by uPARAP/Endo180 is a major pathway of extracellular matrix turnover during malignancy. J Cell Biol 2005, 169:977-985

61. Engelholm LH, List K, Netzel-Arnett S, Cukierman E, Mitola DJ, Aaronson $\mathrm{H}$, Kjøller L, Larsen JK, Yamada KM, Strickland DK, Holmbeck $K$, Danø $K$, Birkedal-Hansen $H$, Behrendt $N$, Bugge $T H$ : UPARAP/Endo180 is essential for cellular uptake of collagen and promotes fibroblast collagen adhesion. J Cell Biol 2003 160:1009-1015. 
62. Wall SJ, Werner E, Werb Z, DeClerck YA: Discoidin domain receptor 2 mediates tumor cell cycle arrest induced by fibrillar collagen. J Biol Chem 2005, 280:40187-40194.

63. lozzo RV: Basement membrane proteoglycans: from cellar to ceiling. Nat Rev Mol Cell Bio/ 2005, 6:646-656.

64. Buck MB, Pfizenmaier K, Knabbe C: Antiestrogens induce growth inhibition by sequential activation of p38 mitogen-activated protein kinase and transforming growth factor-beta pathways in human breast cancer cells. Mol Endocrinol 2004, 18:1643-1657.

65. Shekhar MP, Santner S, Carolin KA, Tait L: Direct involvement of breast tumor fibroblasts in the modulation of tamoxifen sensitivity. Am J Pathol 2007, 170:1546-1560. 